\title{
Sensitivity analysis and uncertainty assessment in water budgets simulated by the variable infiltration capacity model for Canadian subarctic watersheds
}

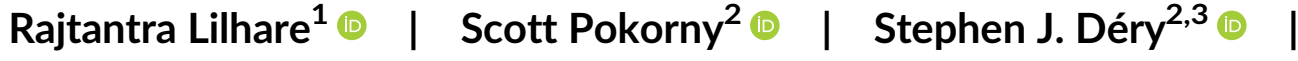 \\ Tricia A. Stadnyk ${ }^{2,3,4}$ @ | Kristina A. Koenig ${ }^{5}$ (c)
}

${ }^{1}$ Natural Resources and Environmental Studies Program, University of Northern British Columbia, Prince George, British Columbia, Canada

${ }^{2}$ Department of Civil Engineering, University of Manitoba, Winnipeg, Manitoba, Canada

${ }^{3}$ Environmental Science and Engineering Program, University of Northern British Columbia, Prince George, British Columbia, Canada

${ }^{4}$ Department of Geography, University of Calgary, Calgary, Alberta, Canada

${ }^{5}$ Water Resources Engineering Department, Manitoba Hydro, Winnipeg, Manitoba, Canada

\section{Correspondence}

Rajtantra Lilhare, Natural Resources and Environmental Studies Program, University of Northern British Columbia, Prince George, British Columbia, Canada.

Email: lilhare@unbc.ca

Funding information

Natural Sciences and Engineering Research Council of Canada, Grant/Award Number: NSERC CRD 44425 RC15-3100; Manitoba Hydro

\begin{abstract}
In this study, we evaluate uncertainties propagated through different climate data sets in seasonal and annual hydrological simulations over 10 subarctic watersheds of northern Manitoba, Canada, using the variable infiltration capacity (VIC) model. Further, we perform a comprehensive sensitivity and uncertainty analysis of the VIC model using a robust and state-of-the-art approach. The VIC model simulations utilize the recently developed variogram analysis of response surfaces (VARS) technique that requires in this application more than 6,000 model simulations for a 30-year (1981-2010) study period. The method seeks parameter sensitivity, identifies influential parameters, and showcases streamflow sensitivity to parameter uncertainty at seasonal and annual timescales. Results suggest that the Ensemble VIC simulations match observed streamflow closest, whereas global reanalysis products yield high flows $\left(0.5-3.0 \mathrm{~mm} \mathrm{day}^{-1}\right)$ against observations and an overestimation (10-60\%) in seasonal and annual water balance terms. VIC parameters exhibit seasonal importance in VARS, and the choice of input data and performance metrics substantially affect sensitivity analysis. Uncertainty propagation due to input forcing selection in each water balance term (i.e., total runoff, soil moisture, and evapotranspiration) is examined separately to show both time and space dimensionality in available forcing data at seasonal and annual timescales. Reliable input forcing, the most influential model parameters, and the uncertainty envelope in streamflow prediction are presented for the VIC model. These results, along with some specific recommendations, are expected to assist the broader VIC modelling community and other users of VARS and land surface schemes, to enhance their modelling applications.
\end{abstract}

\section{KEYWORDS}

hydrological modelling, lower Nelson River basin, sensitivity analysis, uncertainty assessment, VARS, VIC model, VIC parameters, water balance

\section{1 | INTRODUCTION}

Numerical modelling of a river basin remains essential for both climate and ecological studies as it provides vital information about the hydrological cycle and water availability for societies and ecosystems. Although recent developments and advances have been achieved in hydrological modelling and computational power, addressing efficiently the uncertainties in hydrological simulation remains a critical 
challenge (Liu \& Gupta, 2007). There is a growing need for sensitivity and uncertainty assessments associated mainly with the model and input forcing data sets to achieve the hydrological model's optimal performance for decision-making. Input climate forcing for numerical modelling, primarily precipitation and air temperature, are essential for accurate streamflow simulations and water balance calculations (Eum, Dibike, Prowse, \& Bonsal, 2014; Fekete, Vörösmarty, Roads, \& Willmott, 2004; Reed et al., 2004; Tobin, Nicotina, Parlange, Berne, \& Rinaldo, 2011). For cold regions, these input forcing alter the phase and magnitude of modelled variables and cascade through all hydrological processes during numerical simulations, impacting the reliability of model output (Anderson et al., 2008; Tapiador et al., 2012; Wagener \& Gupta, 2005). In Canada, however, numerous studies have also used multiple forcing data sets to assess the performance of hydrological simulations. For example, Sabarly, Essou, Lucas-Picher, Poulin, and Brissette (2016) used four reanalysis products to evaluate the terrestrial branch of the water cycle over Québec, Canada with acceptable results for the period 1979-2008. The question of which forcing data set is the most suitable and accurate to drive hydrological models remains elusive and inconclusive. Steps towards answering that question were undertaken by Pavelsky and Smith (2006) who concluded that observations covered the trends significantly better than two reanalysis products when they assessed the quality of four global precipitation data sets against the discharge observations from 198 pan-Arctic rivers. The bias and uncertainty in global hydrological modelling due to input data sets and associated overestimations or underestimations in modelled streamflows in several river basins have also been identified in previous studies (e.g., Döll, Kaspar, \& Lehner, 2003; Gerten, Schaphoff, Haberlandt, Lucht, \& Sitch, 2004; Nijssen, Schnur, \& Lettenmaier, 2001). Although there may be other uncertainties (e.g., model structure, calibration, soil type, land use, etc.), this paper focuses primarily on the uncertainties due to model parameters and input forcing data sets, which are perhaps the most significant source of uncertainty for any hydrological modelling study (Zhang, Li, Huang, Wang, \& Cheng, 2016).

In practice, many (from tens to hundreds) parameters in most hydrological models lead to dimensionality issues where parameter estimation becomes mostly nonlinear and a high-dimensional problem. Numerous optimization algorithms are available to address these problems (e.g., Abebe, Ogden, \& Pradhan, 2010; Aster, Borchers, \& Thurber, 2013; Beven \& Binley, 1992; Duan, Sorooshian, \& Gupta, 1992; Hill \& Tiedeman, 2007; Vrugt, Diks, Gupta, Bouten, \& Verstraten, 2005; Vrugt, Gupta, Bouten, \& Sorooshian, 2003), but it is not often feasible or necessary to include all these parameters in the calibration and sensitivity analysis (SA) process to obtain efficient optimization and sensitive parameters, respectively. For instance, overparameterization is another well-known problem in land surface modelling (Van Griensven et al., 2006). At present, various SA methods (e.g., qualitative or quantitative, local or global, and screening or refined methods) are used widely in different fields, such as complex engineering systems, physics, and social sciences (Frey \& Patil, 2002; Iman \& Helton, 1988). Given the extensive range of SA methods available, users should have a clear understanding of the methods that are appropriate for a specific application. In general, the variable infiltration capacity (VIC) hydrological model incorporates many parameters (some with physical significance and some statistical), which are used to calibrate the model by various methods. In some cases, parameters with physical significance may be adjusted interactively during calibration. Some parameters may have less influence on model output such that they could be easily ignored. One of the objectives of this study is thus to explore the sensitivity of VIC calibration parameters to reduce the dimensionality issue in model optimization at different timescales and to establish their interannual importance in the calibration and model performance.

In this study, we quantify the uncertainty propagated from available forcing data sets in their surface water balance estimations over the lower Nelson River Basin (LNRB) in northern Manitoba, Canada. To achieve this goal, seven input forcing data sets that are intercompared in our companion paper are ingested into the VIC model over the LNRB (Lilhare, Déry, Pokorny, Stadnyk, \& Koenig, 2019). These data sets are used in various other studies over different Canadian regions (Boucher \& Best, 2010; Islam \& Déry, 2017; Sauchyn, Vanstone, \& Perez-Valdivia, 2011; Seager et al., 2014; Woo \& Thorne, 2006). To our knowledge, this is perhaps the first comprehensive study that collectively utilizes available gridded data sets in hydrological modelling, establishes the most suitable data sets, minimizes the input data uncertainty by evaluating the best performing product, and then propagates input and parameter uncertainty through the model output. Moreover, we consider not only the total uncertainty (i.e., total run-off) but also the apportioned uncertainty in run-offgenerating processes such as precipitation, evapotranspiration (ET hereafter), and soil moisture at annual and seasonal timescales. The main objectives of this study are to (a) examine uncertainty propagated through various input forcing data sets in the VIC model; (b) identify parameter sensitivity of the VIC model to streamflow; and (c) assess streamflow sensitivity to parameter uncertainty in the VIC model over the LNRB.

\section{2 | STUDY AREA}

In this study, the lower Nelson River, which is the downstream segment of the Nelson River system, is selected for the VIC modelling, sensitivity, and uncertainty analyses (Figure 1). The LNRB spans an area of $\sim 90,500 \mathrm{~km}^{2}$ and collects all water from the drainage area upstream of the Nelson River $\left(\sim 970,000 \mathrm{~km}^{2}\right)$ before discharging into Hudson Bay. In the LNRB, the main stem river (Nelson) and its largest tributary-the Burntwood, whose downstream segment carries diverted flows from the Churchill River-have less seasonal flow variability due to streamflow regulation and a large drainage area. Most of the LNRB has gentle slopes, with common channelized lakes moderating flow variability. Wetlands abound within the LNRB, store significant volumes of water, cover large areas, and moderate streamflow responses to rainfall and snowmelt events. Shallow soils and permafrost limit infiltration, groundwater storage, and groundwater flows. To increase its hydroelectric capacity, Manitoba Hydro manages flows 
FIGURE 1 Maps of the lower Nelson River Basin (LNRB). (a) The Nelson River Basin, Churchill River Basin, and LNRB. (b) Major rivers and sub-watersheds within the LNRB; yellow triangles show the hydrometric stations used in this study; white circles denote existing generating stations; and the yellow circle shows a future generating station (currently under construction) by Manitoba Hydro. A red star indicates the Churchill River diversion, and the digital elevation model represents the variable infiltration capacity model domain at $0.10^{\circ}$ resolution

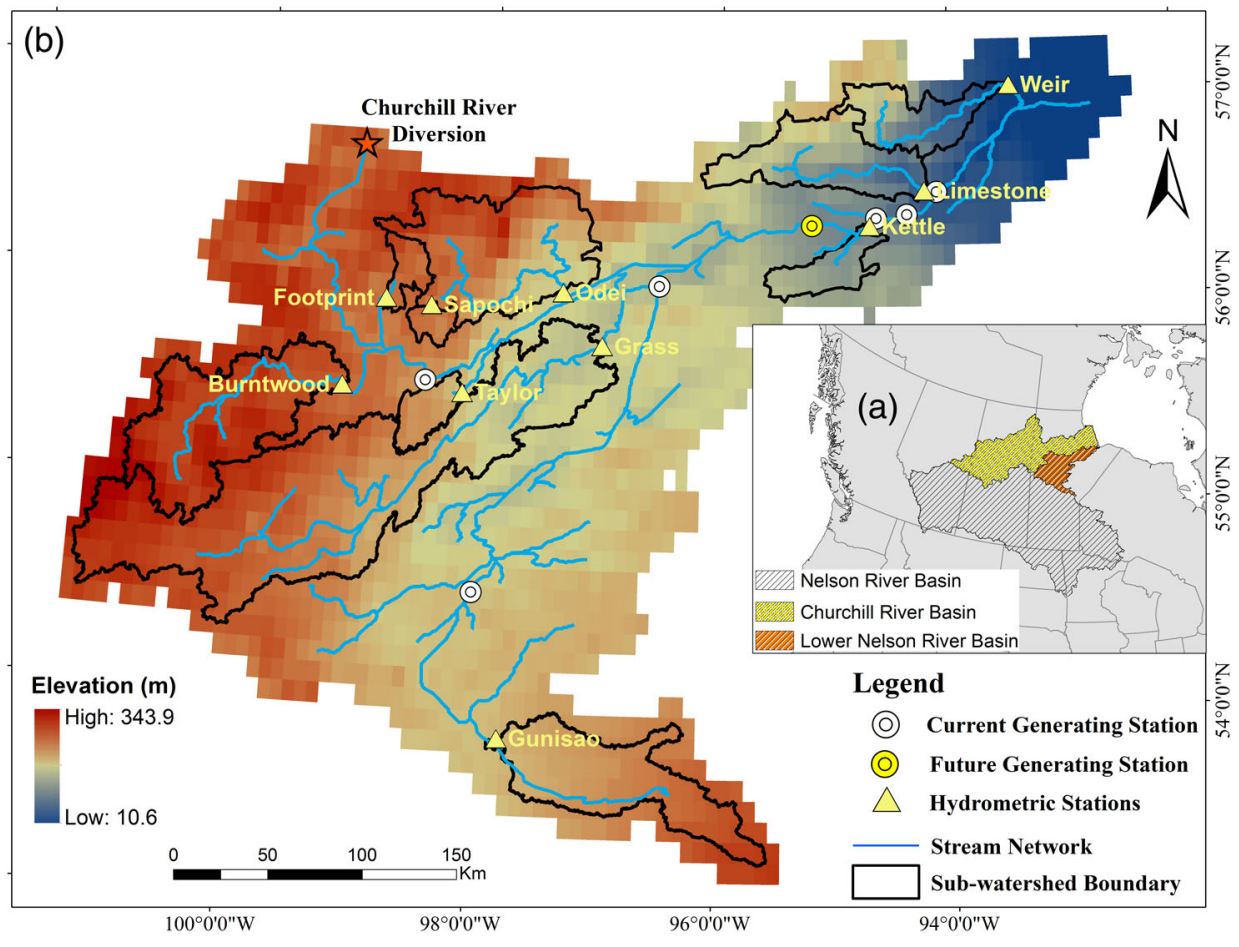

in the LNRB with two major sources of streamflow regulation: the Churchill River diversion and Lake Winnipeg regulation.

The LNRB experiences a subarctic continental climate characterized by moderate precipitation and humidity, cool summers, and cold winters. The snow-free season remains brief, generally beginning in May and ending in October. Most of the precipitation that occurs during the summer months falls as rain, accounting nearly two-thirds of the total annual precipitation. The most expansive land cover class in the LNRB is temperate or subpolar needleleaf forest covering $33 \%$ of its total area with secondary classes being mixed forests (19\%) and temperate or subpolar shrublands (9\%; North American Land Change Monitoring System, 2010). Wetlands (bogs and fens, 21\%) and open surface water (13\%) also prevail in the region. The entire region exhibits low relief with a maximum elevation of $390 \mathrm{~m}$ a.s.l. and average basin slope of $0.037 \%$. Permafrost abounds in the LNRB with the downstream, northeastern portion underlain by continuous (between $90 \%$ to $100 \%$ ) and extensive discontinuous (between $50 \%$ to $90 \%$ ) permafrost (approximately $0.8 \%$ and $9 \%$ of the LNRB, respectively), whereas sporadic discontinuous (between 10\% to 50\%) and isolated permafrost spans $\sim 68 \%$ and $16 \%$ of the LNRB's total area, respectively (Natural Resources Canada, 2010).

\section{MATERIALS AND METHODS}

\section{1 | Data sets}

Soil parameters for the VIC model are sourced from the multiinstitution North American Land Data Assimilation System project at $0.50^{\circ}$ resolution (Cosby, Hornberger, Clapp, \& Ginn, 1984). These soil parameters are then aggregated to the VIC model resolution $\left(0.10^{\circ}\right)$ following Mao and Cherkauer (2009). Frost-related parameters (e.g., bubbling pressure) are extracted from Miller and White (1998) or set to default values (Mao \& Cherkauer, 2009). Land cover data are obtained from the Natural Resources Canada's GeoGratis-Land Cover, and circa 2000-Vector product and vegetation parameters are estimated by following Sheffield and Wood (2007). All land cover classes are mapped into standard VIC model vegetation classes, and the leaf area index for each vegetation class in every grid cell is estimated (Myneni, Ramakrishna, Nemani, \& Running, 1997). Rooting depths are obtained from Maurer, Wood, Adam, Lettenmaier, and Nijssen (2002), whereas other vegetation parameters are taken from Nijssen et al. (2001).

We obtain various gridded forcing data sets for further analysis: the Australian National University spline interpolation (ANUSPLIN), North American Regional Reanalysis (NARR), European Centre for Medium-Range Weather Forecasts interim reanalysis (ERA-Interim), European Union Water and Global Change (WATCH) Forcing Data ERA-Interim (WFDEI), and Hydrological Global Forcing Data (HydroGFD). As well, an inverse distance weighted (IDW) data set constructed from 14 Environment and Climate Change Canada meteorological stations across the LNRB using a squared IDW interpolation technique is also used (see Table 1 for more details). These data sets are assembled to produce the Ensemble data set from 1981 to 2010. Our companion paper (Lilhare et al., 2019) and Text S1 provide a comprehensive intercomparison and additional details of these data sets. The NARR, ERA-I, and HydroGFD daily precipitation and wind speed are obtained from the sum and average of 3-hourly values for a 24-hr period, respectively. To obtain daily maximum and minimum air temperature $\left(T_{\max }\right.$ and $\left.T_{\min }\right)$ for these products, we extract the maximum 
TAB LE 1 VIC intercomparison experiments performed using different forcings (Lilhare et al., 2019)

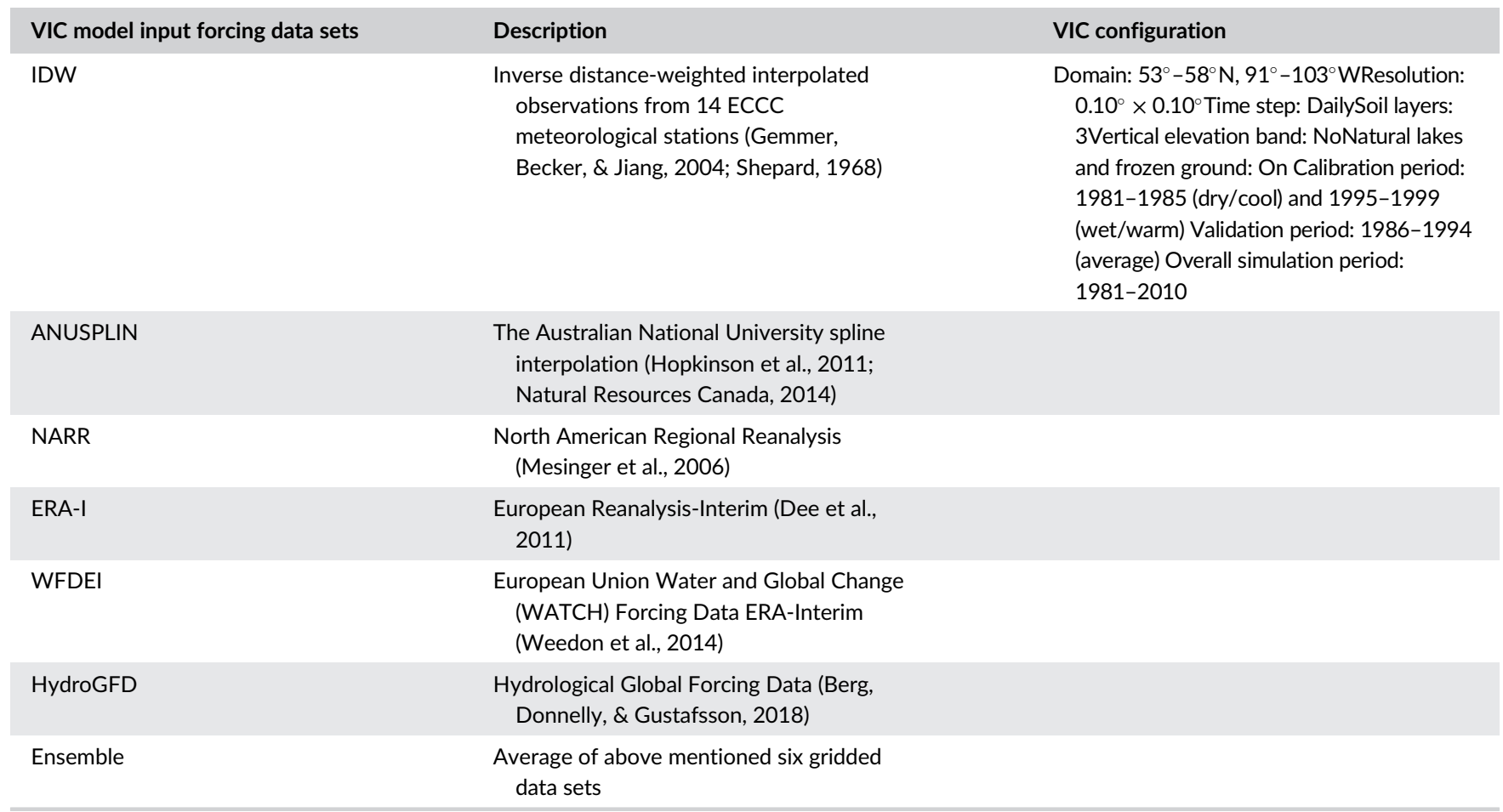

Abbreviation: VIC, variable infiltration capacity.

and minimum value for 1 day from the 3-hourly NARR, ERA-I, and HydroGFD air temperature products. Daily wind speed is not available for the ANUSPLIN and IDW forcing data sets. The observed wind speeds, both upper air and near-surface values, are assimilated in the NARR reanalysis product, and they show satisfactory correspondence with Environment and Climate Change Canada observations (Hundecha, St-Hilaire, Ouarda, El Adlouni, \& Gachon, 2008). Therefore, we use NARR wind speeds to run VIC in combination with the ANUSPLIN and IDW data sets for input forcing. For the Ensemble, daily precipitation, $T_{\max }$ and $T_{\min }$, are derived from the equally weighted average of all six gridded products, whereas the daily wind speed ensemble is calculated from four reanalysis products (NARR, ERA-I, WFDEI, and HydroGFD) as the other two data sets (IDW and ANUSPLIN) do not have such records. The equally weighted ensemble approach has been used previously over global and regional domains to evaluate changes in water balance components under historical and projected future climate conditions (Fowler, Ekström, Blenkinsop, \& Smith, 2007; Fowler \& Kilsby, 2007; Mishra \& Lilhare, 2016; Wang, Bohn, Mahanama, Koster, \& Lettenmaier, 2009).

\section{2 | The VIC model}

In this study, the VIC (version 4.2.d) model (Liang, Lettenmaier, Wood, \& Burges, 1994; Liang, Wood, \& Lettenmaier, 1996) with more recent modifications is used to simulate daily streamflow in full water and energy balance mode (Bowling \& Lettenmaier, 2010; Bowling et al., 2003; Cherkauer \& Lettenmaier, 1999; Table 1). The VIC model grid cells over the LNRB comprise 41 rows and 90 columns with a $5^{\circ}$ range of latitudes $\left(53^{\circ}-58^{\circ} \mathrm{N}\right)$ and a $12^{\circ}$ range of longitudes $\left(103^{\circ}-\right.$ $91^{\circ} \mathrm{W}$ ). The VIC model uses three soil layers, five soil thermal nodes (the default value), and a constant bottom boundary temperature at a damping depth of $10 \mathrm{~m}$ for our study region (Williams \& Gold, 1976). The LNRB's tiles are characterized by soil and vegetation fractions, which are partitioned proportionally within a grid cell. For cold regions hydrology, VIC follows the U.S. Army Corps of Engineers' empirical snow albedo decay curve (USACE, 1956); the total precipitation is distributed based on the $0.10^{\circ}$ grid cells, and the air temperature is adjusted to resolve the precipitation type with a $0^{\circ} \mathrm{C}$ threshold to discriminate rainfall/snowfall. The default single elevation band is used whereby VIC assumes that each grid cell is flat and takes the mean grid elevation into account for simulations over the LNRB. A finite difference algorithm for frozen soil, which tracks soil ice content and represents permafrost, is implemented into the VIC model to improve its modelling abilities (Cherkauer \& Lettenmaier, 1999, 2003). The frozen soil algorithm solves heat fluxes through the soil column using a heat transfer equation (Cherkauer \& Lettenmaier, 1999). This algorithm supersedes the original soil thermal flux equations (Liang, Wood, \& Lettenmaier, 1999) in favour of a more robust numerical technique (Cherkauer \& Lettenmaier, 1999) that simulates soil temperatures at five thermal nodes through the soil column. Natural lakes and wetlands are considered in the model implementation; however, anthropogenic structures (i.e., dams, reservoirs) and flow regulation are not incorporated in the VIC model. The VIC model lake and wetlands algorithm represents the effects of hydrologically disconnected lakes and wetlands by creating its land class that can be added to the grid cell mosaic, in addition to the vegetation and bare soil land classes (Bowling \& Lettenmaier, 2010). It does not represent riparian systems 
that receive water from overbank flow. The energy balance of open water in VIC builds on the work of Hostetler (1991), Hostetler and Bartlein (1990), and Patterson and Hamblin (1988), while that of the exposed wetland vegetation follows Cherkauer and Lettenmaier (1999). Ten of the lower Nelson River's unregulated tributaries (including the unregulated, upstream portion of the Burntwood River) are selected for model calibration, evaluation, and subsequent analyses (Table 2). The routing network and other essential inputs for the routing model (e.g., flow direction, fraction, and mask) are created at $10 \mathrm{~km}$ resolution for the entire LNRB using the $30 \mathrm{~m}$ Shuttle Radar Topography Mission (SRTM) digital elevation model (United States Geological Survey, 2013).

\subsection{1 | Calibration and evaluation}

For VIC model calibration, an optimization process using the University of Arizona Multi-Objective COMplex Evolution Algorithm (MOCOM-UA) minimizes the difference between observed and simulated monthly streamflow at unregulated hydrometric gauge locations within the LNRB (Shi, Wood, \& Lettenmaier, 2008; Yapo, Gupta, \& Sorooshian, 1998). Here, the training parameter set used in the sensitivity and calibration processes comprises six soil parameters: $b_{\text {inf }}$ (infiltration parameter that controls the amount of water infiltrating into the soil with values ranging from 0 to 0.4 , in fractions), $D s_{\max }$ (the maximum velocity of baseflow for each grid cell ranging from 0 to $30 \mathrm{~mm} \mathrm{day}^{-1}$ ), Ws (the fraction of maximum soil moisture where nonlinear baseflow occurs ranging from 0 to 1), D2 and D3 (thickness of the second and third soil layers, which affects the soil moisture storage capacity, ranging from 0.3 to $1.5 \mathrm{~m}$ ), and Ds (fraction of the $D s_{\max }$ parameter at which nonlinear baseflow occurs ranging from 0 to 1). The Nash-Sutcliffe efficiency (NSE; Nash \& Sutcliffe, 1970), Kling-Gupta efficiency (KGE; Gupta, Kling, Yilmaz, \& Martinez, 2009), and Pearson's correlation ( $r$ ) coefficients (for simulated vs. observed monthly streamflows), in addition to percent bias (PBIAS), provide metrics to summarize model performance. Separate calibration using each forcing data set is applied to all 10 sub-basins within the LNRB to determine the most optimized parameters against the observed streamflow. We use a split sample approach to span the variety of relatively dry/wet/warm/cool years. Years 1981-1985 (dry/cool) and 1995-1999 (wet/warm) are used for calibration, and 1986-1994 (average) forms the validation period (Table 1; Lilhare et al., 2019). The MOCOM-UA optimizer searches a group of VIC input parameters using the population method; it attempts to maximize the NSE coefficient between observed and simulated streamflow at each iteration. At each trial, the multiobjective vector consisting of VIC parameters is determined, and the population is ordered by the Pareto rank of Goldberg (1989). In the MOCOM-UA optimization process, the user defines the training parameter set, and these parameters are selected based on the calibration experience from previous studies (Islam \& Déry, 2017; Kang, Gao, Shi, Islam, \& Déry, 2016; Nijssen, Lettenmaier, Liang, Wetzel, \& Wood, 1997; Shi et al., 2008).

\section{3 | Experimental set-up and analysis approach}

A series of different VIC model set-ups is conceived to (a) compare the VIC model's response when forced by different gridded data sets

TAB LE 2 List of 10 selected unregulated hydrometric stations, maintained by the Water Survey of Canada and Manitoba Hydro, for the variable infiltration capacity model calibration and evaluation with sub-watershed characteristics and mean annual discharge (Water Survey of Canada, 2016)

\begin{tabular}{|c|c|c|c|c|c|}
\hline $\begin{array}{l}\text { Station name (gauge identification } \\
\text { number) }\end{array}$ & $\begin{array}{l}\text { Latitude } \\
\left({ }^{\circ} \mathrm{N}\right)\end{array}$ & $\begin{array}{l}\text { Longitude } \\
\left({ }^{\circ} \mathrm{W}\right)\end{array}$ & $\begin{array}{l}\text { Mean sub-watershed } \\
\text { elevation }(\mathrm{m})\end{array}$ & $\begin{array}{l}\text { Gauged drainage } \\
\text { area }\left(\mathrm{km}^{2}\right)\end{array}$ & $\begin{array}{l}\text { Mean annual } \\
\text { discharge }\left(\mathrm{m}^{3} \mathrm{~s}^{-1}\right)\end{array}$ \\
\hline $\begin{array}{l}\text { Burntwood River above Leaf Rapids } \\
\text { (05TE002) }\end{array}$ & 55.49 & 99.22 & 302.4 & 5,810 & 22.9 \\
\hline $\begin{array}{l}\text { Footprint River above Footprint Lake } \\
\text { (05TF002) }\end{array}$ & 55.93 & 98.88 & 273.8 & 643 & 3.2 \\
\hline $\begin{array}{l}\text { Grass River above Standing Stone } \\
\text { Falls (05TD001) }\end{array}$ & 55.74 & 97.01 & 265.0 & 15,400 & 64.6 \\
\hline $\begin{array}{l}\text { Gunisao River at Jam Rapids } \\
\text { (05UA003) }\end{array}$ & 53.82 & 97.77 & 260.9 & 4,610 & 18.0 \\
\hline Kettle River near Gillam (05UF004) & 56.34 & 94.69 & 164.7 & 1,090 & 13.2 \\
\hline Limestone River near Bird (05UG001) & 56.51 & 94.21 & 173.6 & 3,270 & 21.5 \\
\hline $\begin{array}{l}\text { Odei River near Thompson } \\
\text { (05TG003) }\end{array}$ & 55.99 & 97.35 & 253.5 & 6,110 & 34.3 \\
\hline $\begin{array}{l}\text { Taylor River near Thompson } \\
\text { (05TG002) }\end{array}$ & 55.48 & 98.19 & 236.2 & 886 & 5.1 \\
\hline $\begin{array}{l}\text { Weir River above the mouth } \\
\text { (05UH002) }\end{array}$ & 57.02 & 93.45 & 125.8 & 2,190 & 15.6 \\
\hline
\end{tabular}




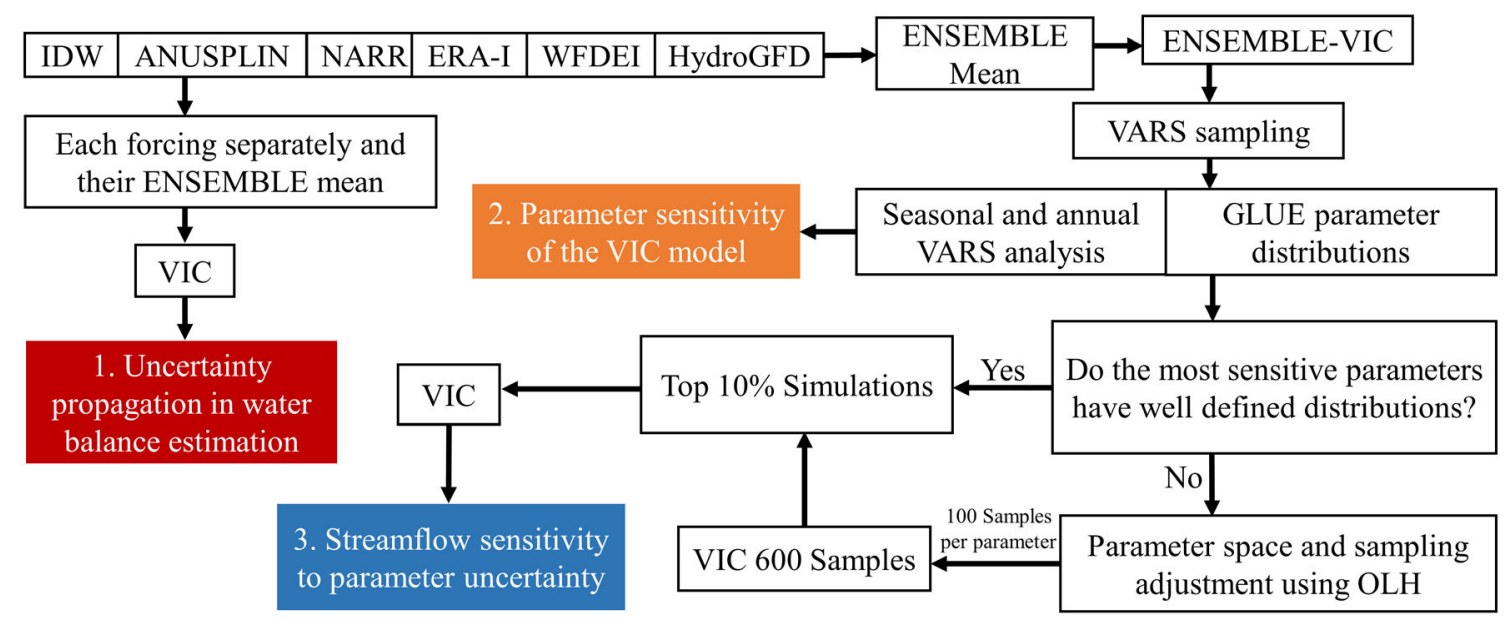

FIGURE 2 Schematic representation of the overall methodology adopted for the propagation, sensitivity, and uncertainty assessment in the VIC modelling over the lower Nelson River Basin. Coloured boxes indicate various objectives of this study. ANUSPLIN, Australian National University spline interpolation; ERA-I, European Reanalysis-Interim; GLUE, generalized likelihood uncertainty estimation; HydroGFD, Hydrological Global Forcing Data; IDW, inverse distance weighted; NARR, North American Regional Reanalysis; OLH, orthogonal Latin hypercube; VARS, variogram analysis of response surfaces; VIC, variable infiltration capacity; WFDEI, European Union Water and Global Change (WATCH) Forcing Data ERA-Interim

(with each simulation referred to as a given "data set VIC" hereafter), (b) evaluate the uncertainties propagated in the water budget estimation using different input forcings, (c) assess VIC parameter sensitivity using the variogram analysis of response surfaces (VARS) at seasonal and annual timescales, and (d) gauge streamflow sensitivity to the VIC model parameter uncertainty (Figure 2). The sensitivity, parameter sampling, and uncertainty methodology are discussed in the following subsections. Moreover, the VIC simulations driven by each forcing data set from 1981-1985 are used to generate a VIC initial state parameter file, to allow model spin-up time for 5 years. This diminishes simulation uncertainty in the calibration, validation, and water balance estimation during the study period. Intercomparison of the seven meteorological data sets from our companion paper suggests that the Ensemble data set provides more robust historical meteorological forcing (Lilhare et al., 2019); therefore, the VIC model forced by the Ensemble data set (i.e., Ensemble VIC) is used as a reference calibration simulation to investigate the propagated uncertainties in water balance estimation from different input forcing data sets.

\subsection{1 | Sensitivity analysis}

VARS, a model parameters SA approach, is applied to the VIC model (Razavi \& Gupta, 2016a, 2016b). The SA approach reduces the number of parameters that numerical models require to consider in the optimization process. Moreover, the set-up is useful for highdimensional optimization problems and can reduce the parametrization uncertainty (Razavi, Sheikholeslami, Gupta, \& Haghnegahdar, 2019). We utilize six VIC model parameters in the "star-based" sampling strategy (STAR VARS), to incorporate VARS in the VIC model and subsequent uncertainty assessment (Razavi \& Gupta, 2016b). Parameter selection is based on the optimal number of VARS simulations and SA conducted by various VIC model users using different SA methods (Demaria, Nijssen, \& Wagener, 2007; Kavetski, Kuczera, \& Franks, 2006; Liang \& Guo, 2003; Liang, Xie, \& Huang, 2003). Specifically, we evaluate the sensitivity of the Kling-Gupta criterion (Gupta et al., 2009; which measures goodness-of-fit between simulated and observed streamflows) to variations in the six VIC model parameters across their feasible ranges. VARS determines parameter reliability through a bootstrapping process and ranks them based on similar parameter occurrence and relative sensitivity (Razavi \& Gupta, 2016a). The SA is performed at seasonal and annual timescales, and if a given model parameter suffers with identifiability issues, then it varies temporally in relative sensitivity and reliability. We use 35 star centres (i.e., 1,925 VIC model runs for each subwatershed) and 0.10 variogram resolution to generate efficient and robust estimates of the VARS sensitivity ranking (Razavi \& Gupta, 2016b).

\subsection{2 | VIC parameter sampling and uncertainty analysis}

Parametric uncertainty is assessed by utilizing the Ensemble input forcing and generalized likelihood uncertainty estimation (GLUE) methodology using 1,925 STAR VARS samples (Beven \& Binley, 1992). Model parameters are sampled from uniform prior distributions and behavioural parameter sets and then used to generate parameter likelihood distributions. The pseudo-likelihood function of KGE is used to assess model performance. The less subjective selection criteria are a common practice in the literature; thus, we use a behavioural parameter set, which subjectively meets the desired performance criteria (Li \& Xu, 2014; Shafii, Tolson, \& Matott, 2015; Stedinger, Vogel, Lee, $\&$ Batchelder, 2008). These methods fail to account for output 
uncertainty; therefore, we use a simple method of selecting the top $10 \%$ of the model simulations. The STAR VARS generates directional variograms in the dimension of each parameter. This implies that once a parameter's directional variogram is sampled for a star centre, it is held constant until being varied for the next star centre; this creates a high density of sampling at one parameter value per star centre. To determine sufficient sampling towards reasonably well-defined parameter uncertainty, we perform a visual inspection of the parameter distribution. If the most sensitive parameters, determined by VARS, show notable deviation from their uninformed priors by visual inspection, then we assume sufficient sampling of the parameter. Further, if the GLUE method, using 1,925 STAR VARS samples, fails to accommodate reasonable likelihood distributions, then we additionally perform orthogonal Latin hypercube (OLH) sampling. The OLH offers uniform sampling and generates an additional $600 \mathrm{VIC}$ parameter samples (Gan et al., 2014).

\section{$4 \mid$ RESULTS}

\subsection{Intercomparison of the VIC simulations}

The NSE (KGE) average scores during calibration and validation are much higher for the NARR VIC, Ensemble VIC, ANUSPLIN VIC, and HydroGFD VIC (NARR VIC, Ensemble VIC, HydroGFD VIC, and WFDEI VIC) compared with other simulations (Figure 3). Despite low $(<0.5)$ NSE and KGE scores from the IDW VIC, ANUSPLIN VIC, ERA-I VIC, and WFDEI VIC simulations, the correlation coefficients remain substantially high for all sub-basins. The negative (positive) biases from IDW VIC, ANUSPLIN VIC, and HydroGFD VIC (ERA-I VIC and WFDEI VIC) contribute to the lower NSE and KGE coefficients, whereas the timing of seasonal flows resembles the observed flows in the IDW VIC and ANUSPLIN VIC. The ERA-I VIC and WFDEI VIC simulations reveal strong positive biases for most of the sub-watersheds
FIGURE 3 Boxplots for monthly calibration (a1-d1) and validation (a2d2) performance metrics, NSE (a1-2), KGE (b1-2), $r$ (simulated vs. observed monthly streamflow; $p<.05$ for all; c1-2) and PBIAS (d1-d2), for 10 subwatersheds within the LNRB based on IDW VIC, ANUSPLIN VIC, NARR VIC, ERA-I VIC, WFDEI VIC, HydroGFD VIC, and ensemble VIC simulations. The black dots within each box show the mean; the red lines show the median; the vertical black dotted lines show a range of minimum and maximum values excluding outliers; and the red + signs show the outliers defined as the values greater than 1.5 times the interquartile range of each metrics. ANUSPLIN, Australian National University spline interpolation; ERA-I, European Reanalysis-Interim; HydroGFD, Hydrological Global Forcing Data; IDW, inverse distance weighted; KGE, Kling-Gupta efficiency; NARR, North American Regional Reanalysis; NSE, Nash-Sutcliffe efficiency; PBIAS, percent bias; VARS, variogram analysis of response surfaces; VIC, variable infiltration capacity; WFDEI, European Union Water and Global Change (WATCH) Forcing Data ERA-Interim
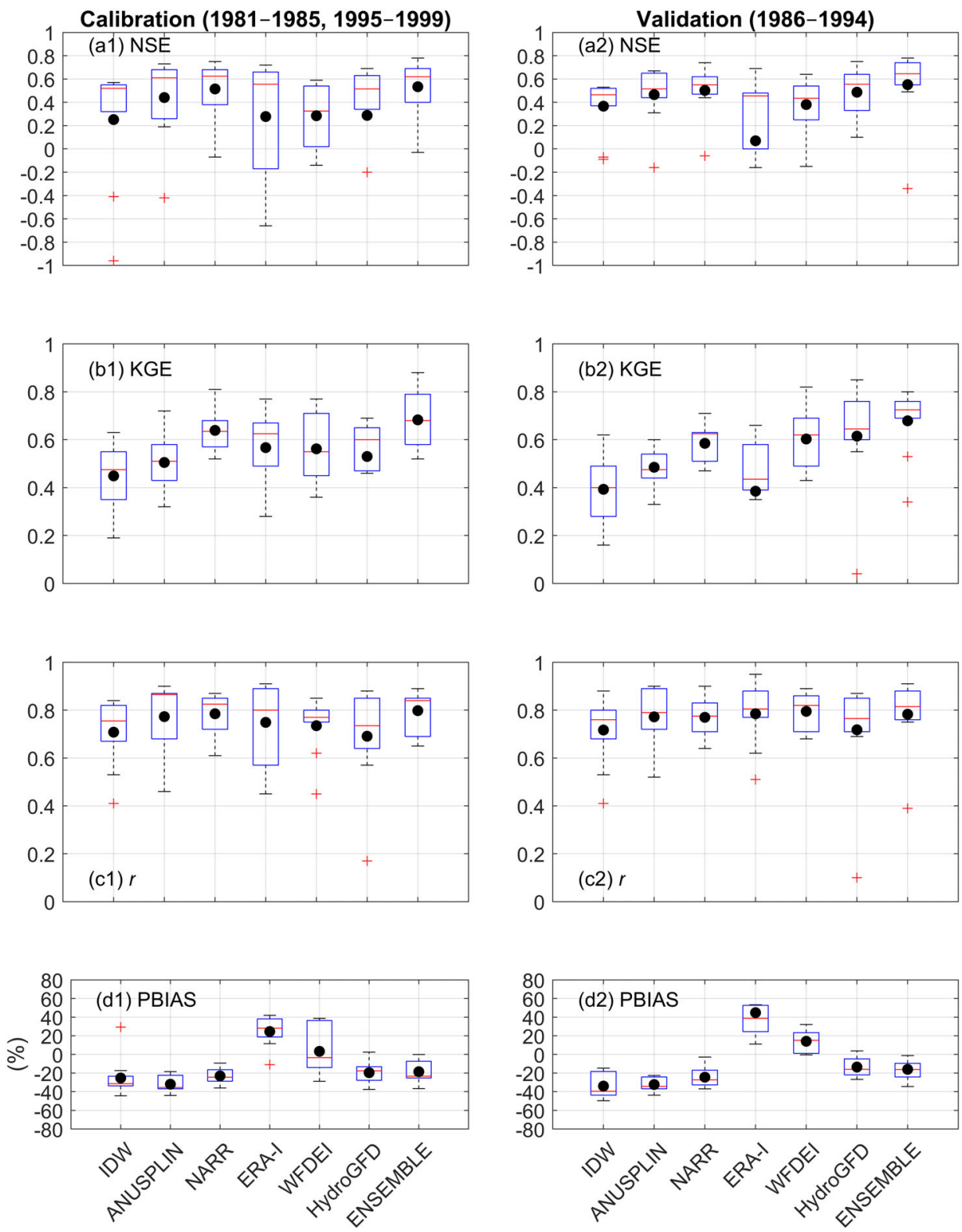

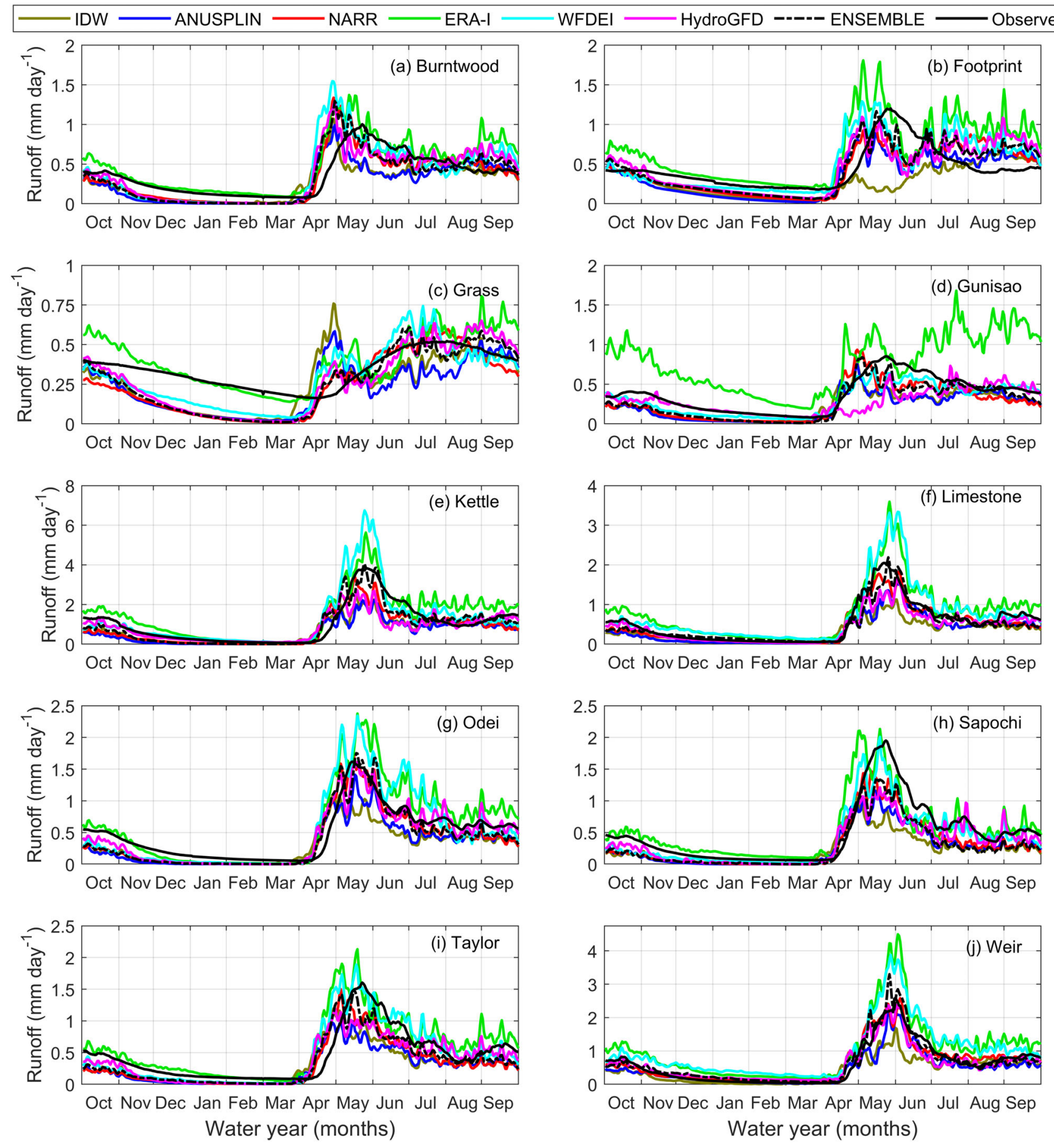

FIGURE 4 Simulated and observed daily run-off $\left(\mathrm{mm} \mathrm{day}^{-1}\right)$ averaged over water years 1981-2010 for the lower Nelson River Basin's 10 unregulated sub-basins. An external routing model is used to calculate run-off for the IDW VIC, ANUSPLIN VIC, NARR VIC, ERA-I VIC, WFDEI VIC, HydroGFD VIC, and Ensemble VIC simulations. Note that $y$-axis scales vary between panels. ANUSPLIN, Australian National University spline interpolation; ERA-I, European Reanalysis-Interim; HydroGFD, Hydrological Global Forcing Data; IDW, inverse distance weighted; NARR, North American Regional Reanalysis; WFDEI, European Union Water and Global Change (WATCH) Forcing Data ERA-Interim

due to their wet biases in the precipitation data sets (Lilhare et al., 2019); however, they show acceptable NSE and KGE coefficients $(\geq 0.5)$ for most of the sub-basins.

Comparison of simulated daily run-off against the observed hydrometric records reveals satisfactory model performances from the NARR VIC and Ensemble-VIC, whereas the IDW VIC and ANUSPLIN VIC run-off is considerably low for all sub-watersheds (Figure 4). ANUSPLIN VIC and IDW VIC run-off shows substantial disagreement with the observed hydrograph, especially in the Kettle, Limestone, Odei, Sapochi, and Weir sub-basins, owing to the dry bias 
and undercatch issue in the precipitation data. The ERA-I VIC and WFDEI VIC simulations overestimate summer and autumn run-off and capture reasonably well winter and spring flows for all sub-watersheds. Simulated flows for the Burntwood, Footprint, and Taylor subwatersheds from all VIC simulations are comparable in magnitude with observations, but the timing is considerably shifted ( 20 days), yielding more spring run-off and earlier decline of summer recession flows. The NARR air temperature is warmer among all other data sets during winter, spring, and autumn. This improves the snowmelt-driven run-off in the NARR-VIC simulation, causing a better representation of simulated flows for these seasons over each sub-watershed. The Ensemble VIC and NARR VIC simulations exhibit satisfactory hydrographs with $\geq 0.5 \mathrm{NSE}$ and KGE scores in most of the sub-basins (Figures 3 and 4).

\section{2 | Uncertainty in the water budget estimation}

The average annual precipitation and VIC-simulated water budgets, which are important factors driving changes in total run-off, from all input forcing and their standard deviations (SD) are estimated to find the uncertainty in annual water budgets over the LNRB's sub-basins (Tables 3 and S1). For 1981-2010, the Gunisao sub-watershed shows high average annual inter-data set variability $\left(52.7 \mathrm{~mm}\right.$ year $\left.{ }^{-1}\right)$ in precipitation that results in $61.5,50.0$, and $88.8 \mathrm{~mm} \mathrm{year}^{-1} \mathrm{SD}$ in the total run-off, ET, and average soil moisture, respectively. The Gunisao (southern outlier in the study area, where air temperatures are much warmer than other sub-basins) generates the lowest total run-off despite the highest annual precipitation. This situation arises through the compensating effect of the highest ET values in the LNRB and appreciable precipitation variability that contributes to overall uncertainty for this sub-basin. A somewhat similar pattern arises in the Grass where a decrease in precipitation uncertainty yields less deviation in total run-off; for example, the Grass sub-watershed exhibits
$26.7 \mathrm{~mm}$ year $^{-1}$ deviation in precipitation, which results in $19.1 \mathrm{~mm}$ year $^{-1}$ deviation in total run-off, smallest among all subbasins. The smaller Sapochi, Footprint, and Taylor (gauged are$a<900 \mathrm{~km}^{2}$ ) sub-basins manifest similar inter-data set errors (>29 $\mathrm{mm} \mathrm{year}^{-1}$ ) for annual precipitation. Further, relatively larger sub-watersheds (i.e., Gunisao and Odei) show significant differences in the $S D$, which reveal higher spatial variability from different forcing data sets.

Area-averaged seasonal total run-off (TR) shows higher uncertainty for relatively large sub-watersheds (e.g., Gunisao, Kettle, Limestone, Odei, and Weir), especially in spring and summer (Figures 5 and 6b1-4). The Ensemble VIC TR (black dots) matches closely the average of the remaining VIC simulations (red bars, referred to as multidata VIC hereafter) for all sub-basins (Figure 6). The Ensemble VIC captures multidata VIC spring TR closely in eight out of 10 sub-watersheds, whereas two others show underestimation (Figure 6b2). This underestimation persists in summer, which could arise from the extension of calibrated parameters to the entire study period (Figure 6b2-3). This approach may be unable to represent long-term daily and seasonal run-off for these sub-basins. Interseasonal air temperature analysis shows that due to extreme minimum air temperature in winter, simulated multidata and Ensemble VIC TR over each subwatershed are low and result in less uncertainty between simulations. The simulated error increases in early spring and persists until late autumn, consistent with seasonal precipitation for all sub-watersheds. For annual TR estimates, the Gunisao, Kettle, Limestone, and Weir sub-watersheds reveal high intersimulation error, whereas relatively smaller sub-basins show less deviation and better TR estimates from Ensemble VIC (Figure S3).

The Gunisao and Kettle sub-basins attain 451.8 and $373.4 \mathrm{~mm}$ average annual ET, respectively, which are the maximum and minimum values among all other sub-basins (Table 3). Regional ET maps from Natural Resources Canada (2016) show 350 to $450 \mathrm{~mm}$ average annual ET over the LNRB that satisfy the average ET estimate
TABLE 3 Components of the simulated water budgets in the lower Nelson River Basin's sub-watersheds, with average annual values for 1981-2010. The PCP based on the mean of six forcing data sets and other terms are the TR, ET, and average SM, all based on the mean of variable infiltration capacity simulations from six different input forcing data sets. SD shows intervariable infiltration capacity simulations variation in the water balance estimations

\begin{tabular}{|c|c|c|c|c|c|c|c|c|}
\hline \multirow[b]{2}{*}{ Sub-basins } & \multicolumn{2}{|c|}{$\mathrm{PCP}(\mathrm{mm})$} & \multicolumn{2}{|c|}{$\mathrm{TR}(\mathrm{mm})$} & \multicolumn{2}{|c|}{ ET (mm) } & \multicolumn{2}{|c|}{$\mathrm{SM}(\mathrm{mm})$} \\
\hline & Mean & $S D$ & Mean & $S D$ & Mean & $S D$ & Mean & $S D$ \\
\hline Burntwood & 502.8 & 29.6 & 97.1 & 23.8 & 408.7 & 17.5 & 77.4 & 14.0 \\
\hline Footprint & 521.0 & 35.5 & 109.6 & 31.3 & 408.3 & 34.6 & 167.1 & 78.3 \\
\hline Grass & 508.2 & 26.7 & 92.8 & 19.1 & 412.0 & 21.4 & 168.8 & 55.6 \\
\hline Gunisao & 546.6 & 52.7 & 93.3 & 61.5 & 451.8 & 50.0 & 150.5 & 88.8 \\
\hline Kettle & 519.6 & 47.2 & 148.6 & 46.9 & 373.4 & 23.3 & 83.5 & 15.2 \\
\hline Limestone & 511.6 & 44.9 & 132.2 & 48.0 & 380.1 & 23.4 & 93.1 & 24.2 \\
\hline Odei & 525.3 & 35.3 & 148.2 & 44.6 & 379.8 & 29.9 & 89.7 & 14.7 \\
\hline Sapochi & 524.5 & 34.3 & 109.1 & 28.0 & 417.7 & 36.7 & 94.4 & 18.8 \\
\hline Taylor & 522.2 & 29.4 & 137.6 & 32.6 & 385.9 & 27.0 & 91.5 & 13.4 \\
\hline Weir & 508.3 & 44.7 & 129.6 & 45.8 & 380.6 & 21.9 & 91.3 & 25.2 \\
\hline Mean & 519.0 & 38.0 & 119.8 & 38.1 & 399.8 & 28.6 & 110.7 & 34.8 \\
\hline
\end{tabular}

Abbreviations: ET, evapotranspiration; PCP, precipitation; SD, standard deviation; SM, soil moisture; TR, total runoff. 

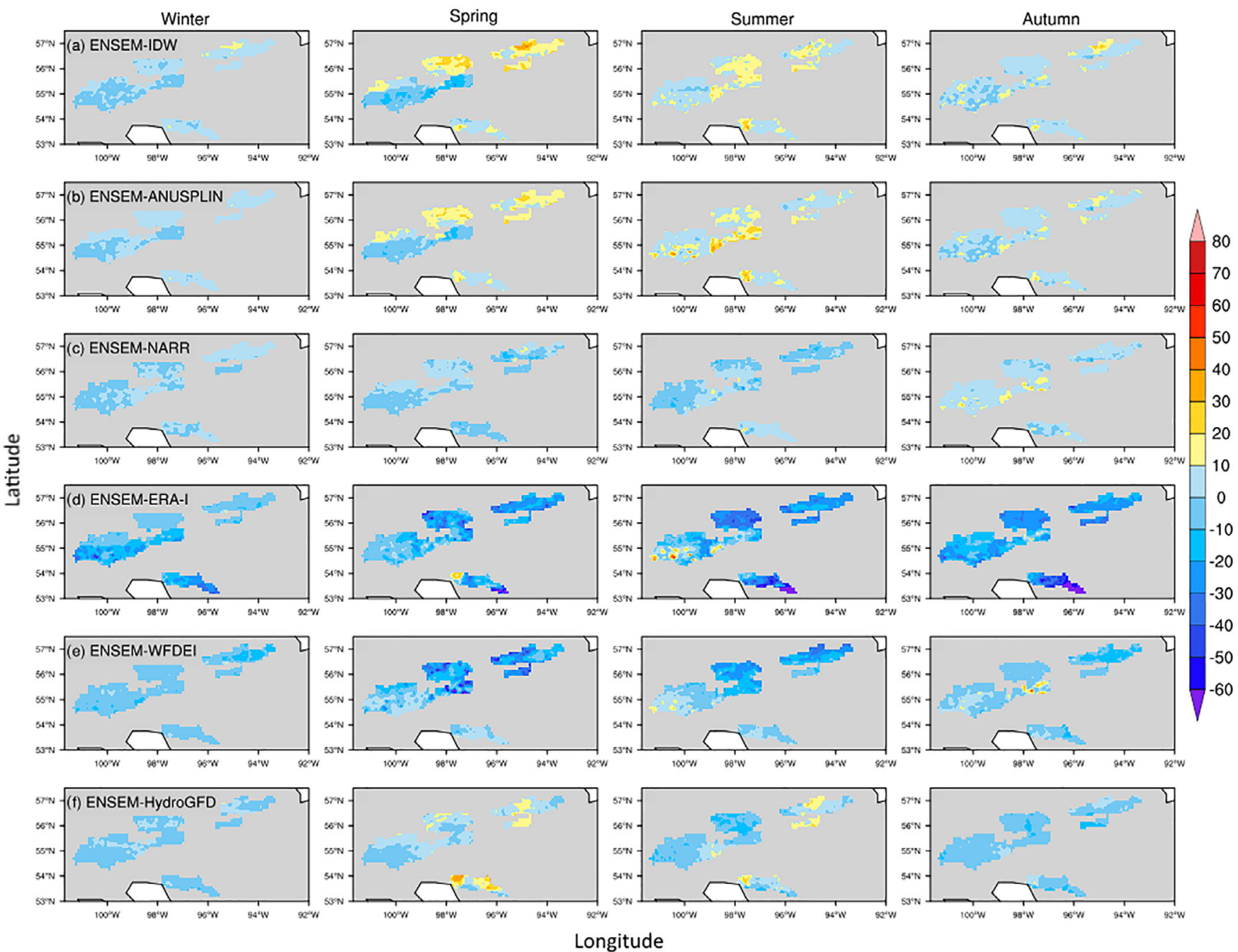

FIGURE 5 Spatial differences of seasonal total run-off $(\mathrm{mm})$ for the lower Nelson River Basin's 10 unregulated sub-basins based on Ensemble VIC (ENSEM) minus (1st row) IDW VIC, (2nd row) ANUSPLIN VIC, (3rd row) NARR VIC, (4th row) ERA-I VIC, (5th row) WFDEI VIC, and (6th row) HydroGFD VIC simulations, water years 1981-2010, for winter, spring, summer, and autumn. ANUSPLIN, Australian National University spline interpolation; ERA-I, European Reanalysis-Interim; HydroGFD, Hydrological Global Forcing Data; IDW, inverse distance weighted; NARR, North American Regional Reanalysis; VIC, variable infiltration capacity; WFDEI, European Union Water and Global Change (WATCH) Forcing Data ERAInterim

from VIC for the study period (1981-2010). Due to cold air temperatures in winter, Ensemble VIC ET is lower $(<3 \mathrm{~mm})$ and corresponds well with the average value (red bars) of other VIC simulations for all sub-watersheds (Figure 6c1-4). It increases through spring $(\sim 100 \mathrm{~mm})$ and peaks in summer $(\sim 250 \mathrm{~mm})$ with 35-mm multidata VIC simulation error, which can be attributed to a substantial rise in air temperature and precipitation. The multidata VIC SD shows identical values in autumn that essentially reveals less regional variability in ET estimates $(\sim 60 \mathrm{~mm})$ from all forcing data sets over the LNRB's sub-basins. Depleted soil moisture conditions induce basin water limitations that yield uncertainty in ET estimates (Figure S1); for example, the largest sub-watersheds (Grass and Gunisao) within the LNRB show higher uncertainty in ET estimates. As the Ensemble data set assigns equal weight and each data set is equally likely to represent the truth, then the Ensemble VIC simulation indeed better represents the winter, spring, and autumn ET with overestimation in summer for all sub-basins (Figures 6c1-4 and S1). For annual ET, the Gunisao and Sapochi sub-basins show high variability within VIC simulations, but other sub-watersheds have less intersimulation error (Figure S3).

The LNRB's water balances vary within each sub-basin depending on the magnitude and timing of precipitation and air temperatures obtained from different input forcing data sets (Table 3 and S1). For instance, long-term ERA-I VIC and WFDEI VIC simulations show higher mean TR that results in higher soil moisture (SM) levels for each sub-basin (Figures 5 and S2). However, Ensemble VIC estimates nearly similar seasonal SM conditions as calculated by the average of the six other VIC simulations for most subbasins (Figure 65d1-4). Among all other seasons, the highest SM occurs in spring followed by summer and autumn due to seasonal 

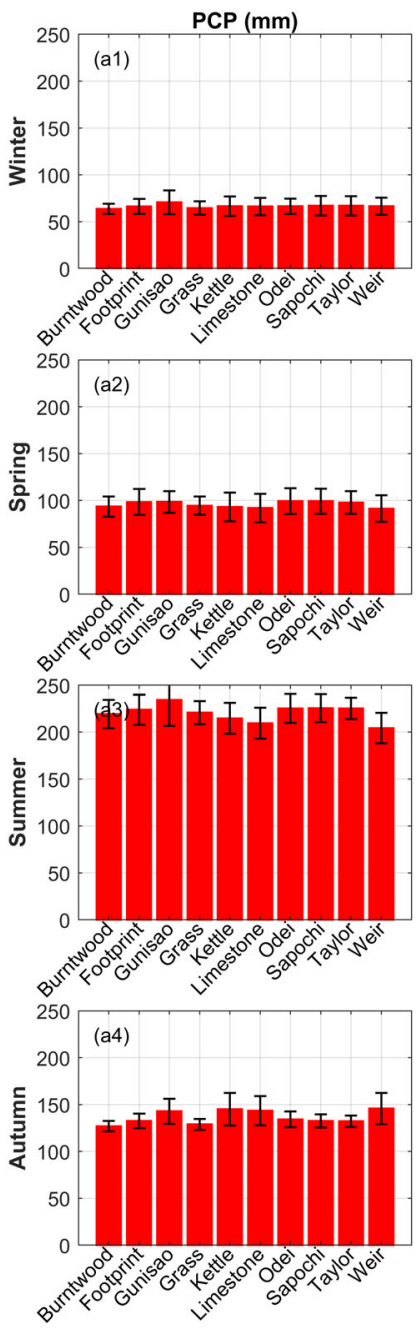
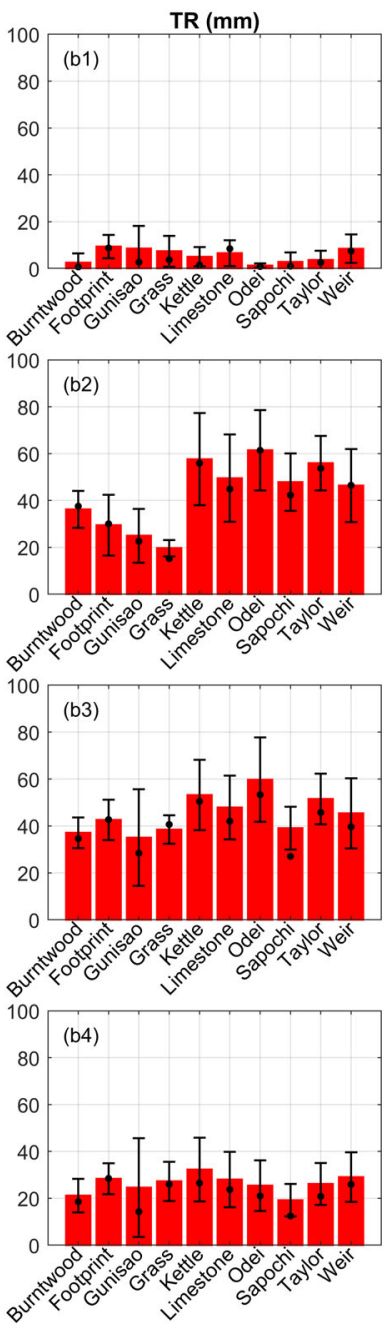
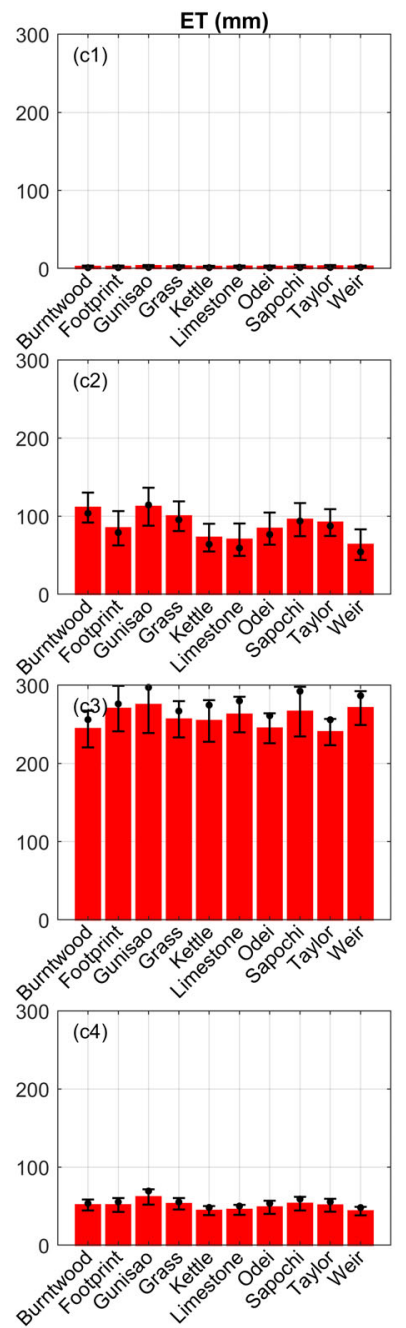
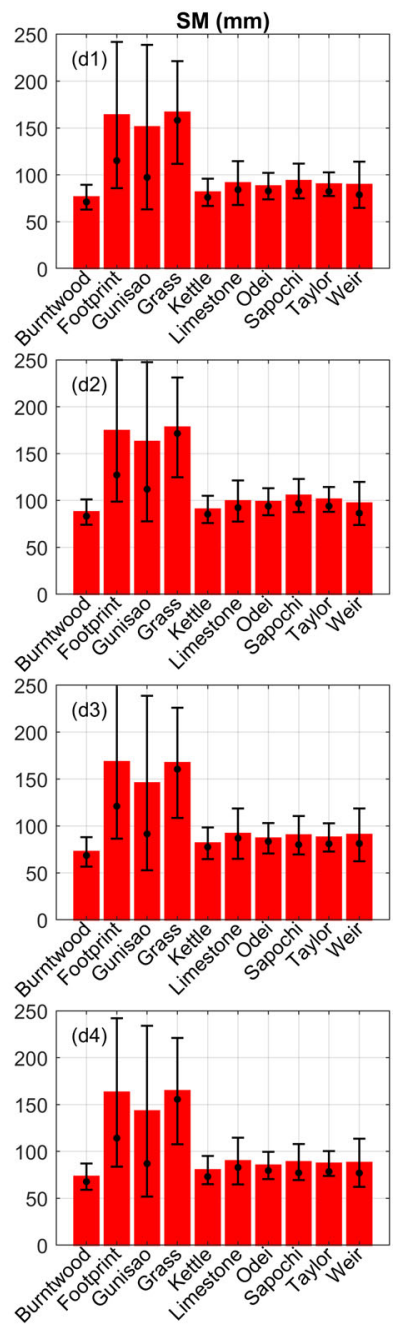

FIGURE 6 Area-averaged variable infiltration capacity (VIC)-simulated seasonal water balance mean (mm) of PCP (a1-4), TR (b1-4), ET (c1-4), and SM (d1-4), represented by different columns, for the lower Nelson River Basin's 10 unregulated sub-basins, water years 1981-2010, for the winter (1st row), spring (2nd row), summer (3rd row), and autumn (4th row) seasons. Red bars show the average of VIC simulations from six forcing data sets (except Ensemble), black error bars indicate inter-VIC simulation variation among IDW VIC, ANUSPLIN VIC, NARR VIC, ERA-I VIC, WFDEI VIC, and HydroGFD VIC, whereas black dots represent the water balance estimation from Ensemble VIC. ANUSPLIN, Australian National University spline interpolation; ERA-I, European Reanalysis-Interim; HydroGFD, Hydrological Global Forcing Data; IDW, inverse distance weighted; NARR, North American Regional Reanalysis; VIC, variable infiltration capacity; WFDEl, European Union Water and Global Change (WATCH) Forcing Data ERA-Interim

transitions and snowmelt run-off, which are more evident in relatively large sub-watersheds (Burntwood, Gunisao, Grass, Limestone, and Weir; Figure 6d1-4). These increased SM values for spring, summer, and autumn show concomitant effects on run-off during these seasons. Furthermore, the Footprint sub-watershed is smaller relative to others; however, it shows considerable inter-data set variation $(\sim 90 \mathrm{~mm})$ in $\mathrm{SM}$ for all seasons. Moreover, eight out of 10 sub-basins demonstrate substantial multi-data sets uncertainty in SM for all seasons, but mean seasonal SM is well captured by the Ensemble VIC for these sub-watersheds. However, large uncertainty in SM also suggests excess water availability that goes either into the TR or ET during these seasons. The highest annual SM arises in the Grass, Footprint, and Gunisao sub-basins with substantial interdata sets variation, whereas other sub-watersheds show less error in SM simulations with nearly identical annual values (Figures S2 and S3).

\subsection{Model parameter sensitivity and uncertainty}

Figure 7a-c shows results from VARS using values from the integrated VARS (IVARS) between $0 \%$ and $50 \%$ of the parameter ranges (IVARS 50), as suggested in the VARS tool manual for a single global sensitivity metric (Razavi \& Gupta, 2016a, 2016b). The hydrologically active depth (D2) of soil for movement and storage of water is by far the most important parameter that contributes $24-66 \%$ of the sensitivity across all sub-watersheds. The next most important parameter is $b_{\text {inf }}$, which accounts for approximately $8-48 \%$ of KGE sensitivity 

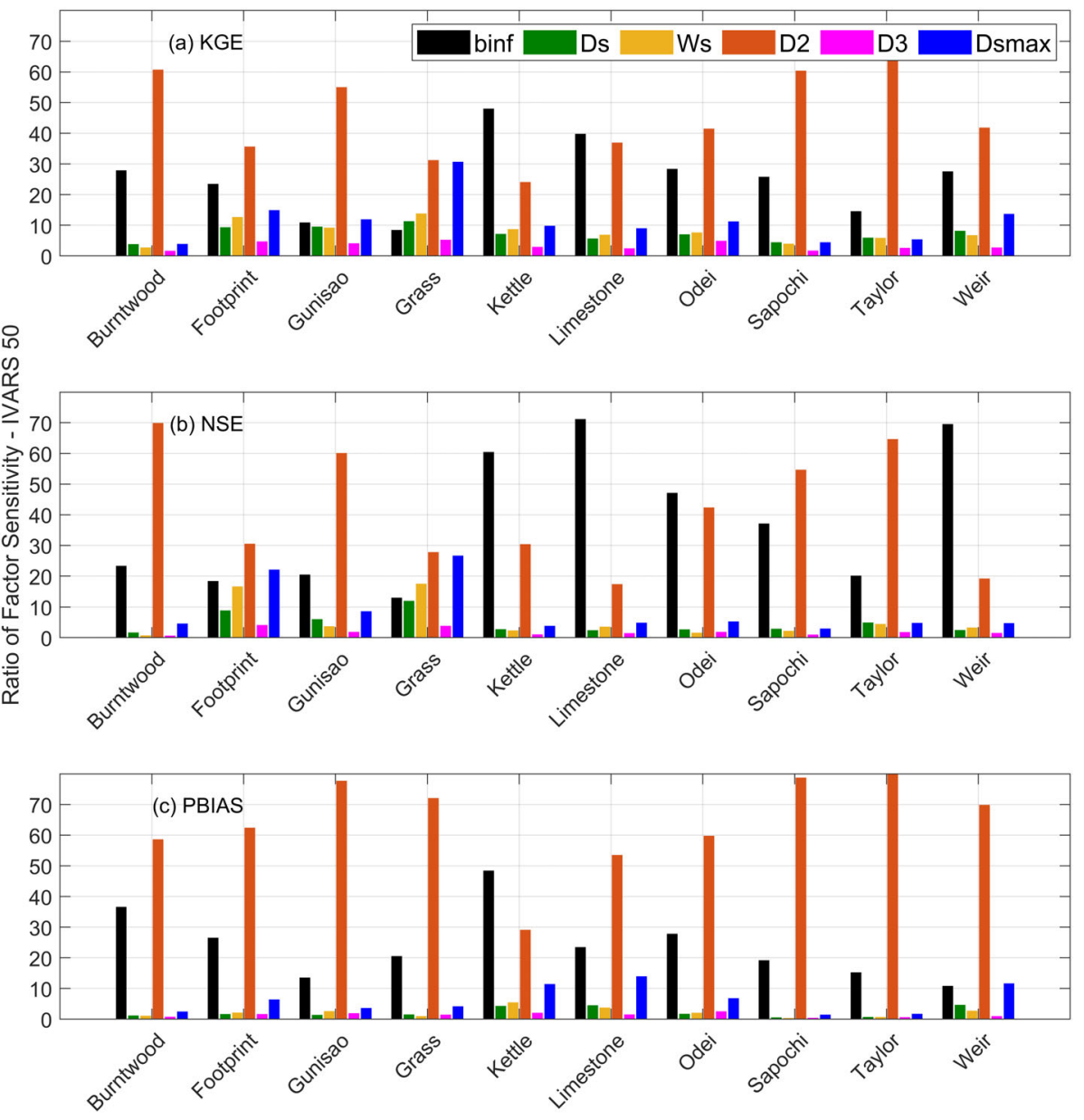

FIGURE 7 Ratio of factor sensitivity (\%) of IVARS 50 for each parameter at annual scale over all sub-watersheds of the lower Nelson River Basin for the three model performance metrics (1981-2010): (a) KGE, (b) NSE, and (c) PBIAS. Ratio of factor sensitivity is estimated by normalizing IVARS

50 values in each case, so they add up to $100 \%$ for all parameters. IVARS, integrated variogram analysis of response surfaces; KGE, Kling-Gupta efficiency; NSE, Nash-Sutcliffe efficiency; PBIAS, percent bias across all sub-watersheds. Together, these two parameters contribute to nearly $40-88 \%$ of the KGE sensitivity. In the Grass River subwatershed, $D s_{\max }$, which is the maximum velocity of baseflow for each grid cell, also becomes important $(\sim 30 \%)$ in controlling the amount of run-off generated at the sub-basin outlet. Note that physically interlinked parameters (D2 and Ds $s_{\max }$ ) together have almost the same sensitivity ratio in the Grass River. Ds (fraction of the $D s_{\max }$ parameter) is the third most important parameter, and Ws, the fraction of maximum soil moisture, is also among the more influential parameters in most of the sub-watersheds. Seasonal sensitivity of model parameters changes substantially; for example, in winter, Ds and Ds $s_{\max }$, which control baseflow, become the most sensitive parameters ( $>25 \%$ ) over all sub-basins, whereas in spring and summer, D2 still plays a dominant role in computing sub-surface flow (Figure S4a). Autumn shows $D s_{\max }$ as the most sensitive parameter because most of the water comes from baseflow during this season.

For NSE, the D2 parameter becomes dominant by a large margin in six out of 10 sub-basins, responsible for $28-70 \%$ of the model sensitivity in these sub-watersheds (Figure 7b). This is not the case for the other four sub-basins (Kettle, Limestone, Odei, and Weir) where $b_{\text {inf }}$ remains the most influential factor controlling predictions of low flows. For the Footprint and Grass, Ws is also influential ( 17\%). Ws emerges as the third most important parameter in most of the subbasins. Seasonal sensitivity of model parameters changes substantially; for example, in winter, $\mathrm{Ds}$ and $D s_{\max }$, which control baseflow, become the most sensitive parameters over all sub-basins, whereas in spring and summer, $b_{\text {inf }}$ and D2 play dominant roles in establishing streamflow (Figure S4b). The $b_{\text {inf }}$ parameter shows $>45 \%$ ratios of factor sensitivity in spring for most of the sub-watersheds that reflects excess water availability for infiltration during snowmelt seasons. Autumn shows Ds $\max _{\max }$ and D2 as the most sensitive parameters because they are responsible in generating seasonal peak flows.

The total flow volume measured by PBIAS shows D2 as the most influential parameter that determines maximum water storage in soils and thus streamflow (Figure 7c). The ratio of sensitivity for this parameter exceeds $50 \%$ for nine sub-basins and nears $80 \%$ in three of them. Unlike the KGE and NSE cases, the baseflow parameters (Ds and $D s_{\max }$ ) are not important for PBIAS because they have no effect on the total flow volume. Overall, for PBIAS, $b_{\text {inf }}$ and D2 are influential parameters followed by $D s_{\max }$. This is due to the influence of all these parameters in controlling surface and subsurface water storages. In all sub-basins, the depth of the second soil layer is more important than the third soil layer. This is perhaps because (a) the third layer is much thicker than the other two layers and (b) the second layer has a larger control on infiltration and ET. Seasonal sensitivity of model parameters for PBIAS is similar to KGE and NSE as the sensitive parameters (i.e., D2, $b_{\text {inf }}$, Ds, and $D s_{\max }$ ) are responsible for streamflow magnitudes and interlinked with each other (Figure S4c). 
Minimum and maximum values for streamflow over the LNRB's sub-watersheds are 74-274 $\mathrm{mm} \mathrm{year}^{-1}$ (Sapochi) and 495-955 mm year ${ }^{-1}$ (Kettle; Figure 8). Greater range is observed for streamflow in relatively small sub-basins such as the Weir, Kettle, and Footprint, as the VARS provides parameter samples within a broad

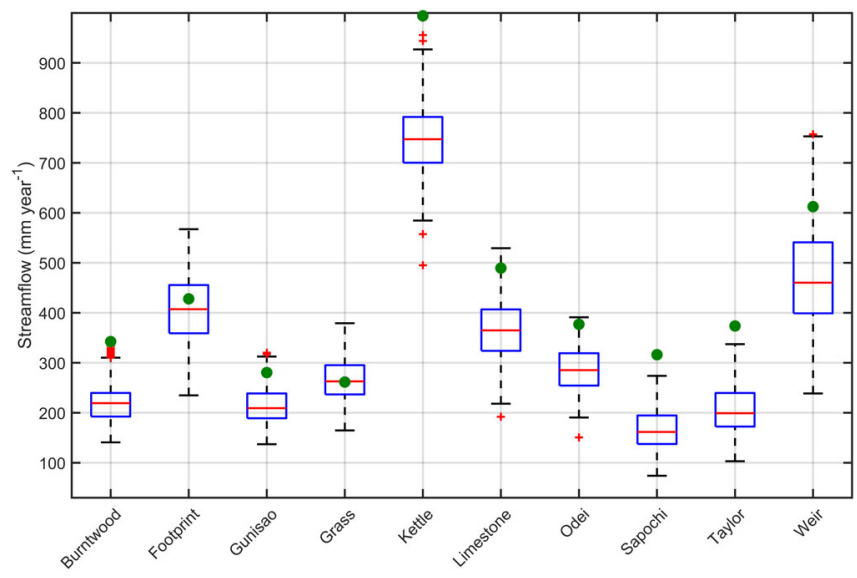

FIGURE 8 Annual streamflow sensitivity to parameter uncertainty for all 10 lower Nelson River Basin sub-watersheds. The green dots show streamflow associated with the control run (calibration); the red lines show the median; the vertical black dotted lines show a range of minimum and maximum values excluding outliers; and the red + signs show the outliers defined as the values greater than 1.5 times the interquartile range of annual streamflow range over small areas. This may also occur due to the combined overall uncertainty from other mass fluxes (i.e., ET, soil moisture, etc.). This analysis shows a range of potential variability that the mean annual streamflow has, which is intended to provide the reader with an estimation of the model uncertainty.

\subsection{Uncertainty assessment of the VIC model parameters using $\mathrm{OLH}$}

In this section, we demonstrate applicability and performance of the OLH to identify and estimate VIC model parameters and their associated uncertainty bounds. Input forcing data and model structure are held constant in this analysis, so that the entire uncertainty in streamflow simulation may be attributed to VIC parameters. Uniform distributions are obtained on the parameter ranges from $\mathrm{OLH}$, and the behavioural parameter sets are used to generate parameter likelihood distributions. As stated earlier, we obtained 600 samples by using six major VIC model parameters in the OLH; therefore, parameter likelihood distributions derive from $600 \mathrm{VIC}$ simulations (Figure 9). These distributions illustrate two points: first, the likelihood distribution of $b_{\text {inf }}$, which is also the most sensitive parameter among others, nears the upper boundary of the predefined parameter range. This can be an indication of a higher $b_{\text {inf }}$ value that is important for these subbasins. Second, the likelihood distribution for D2 captures only a small space of the predefined range, whereas D3 covers almost the entire
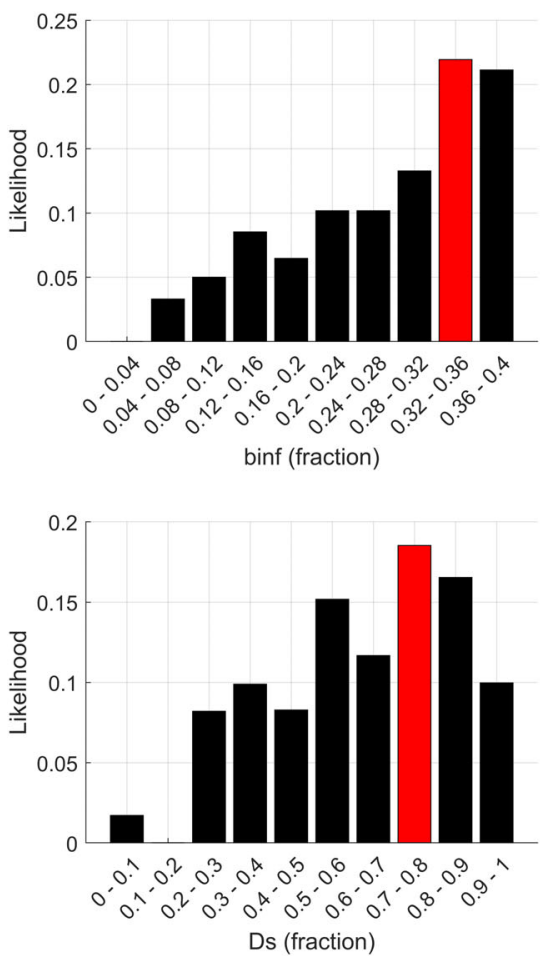
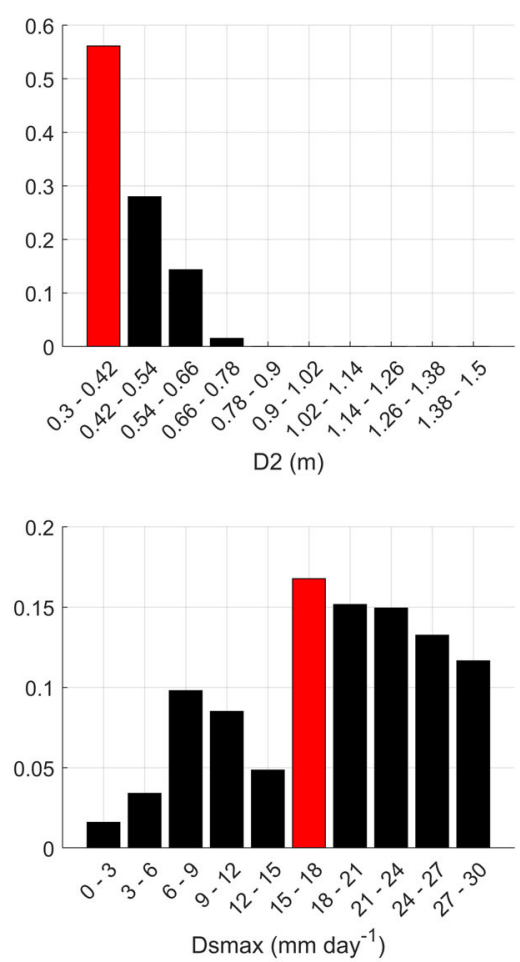
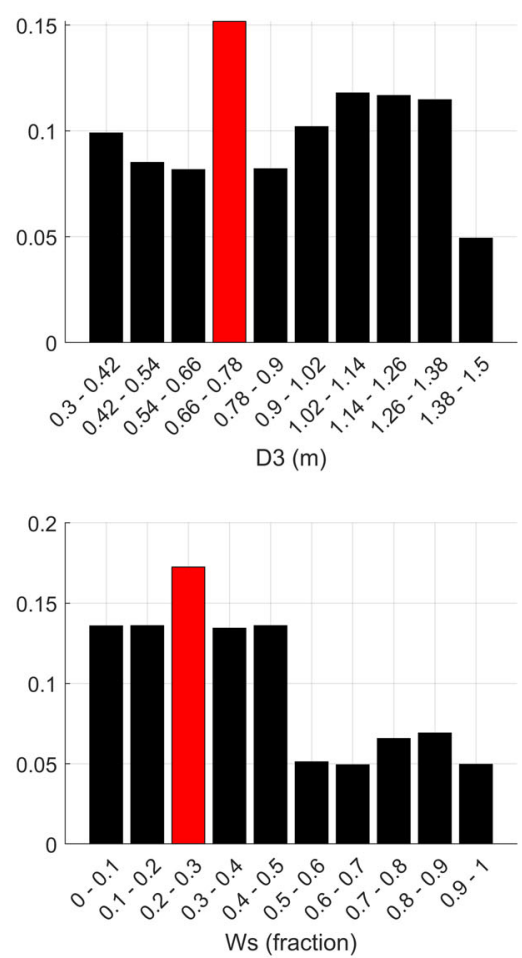

FIGURE 9 Average likelihood distribution of the variable infiltration capacity parameters using 600 samples generated after the orthogonal Latin hypercube sampling over all 10 sub-watersheds of the lower Nelson River Basin. Red bars show the maximum likelihood of parameter range to the model performance metric (Kling-Gupta efficiency) for the lower Nelson River Basin 

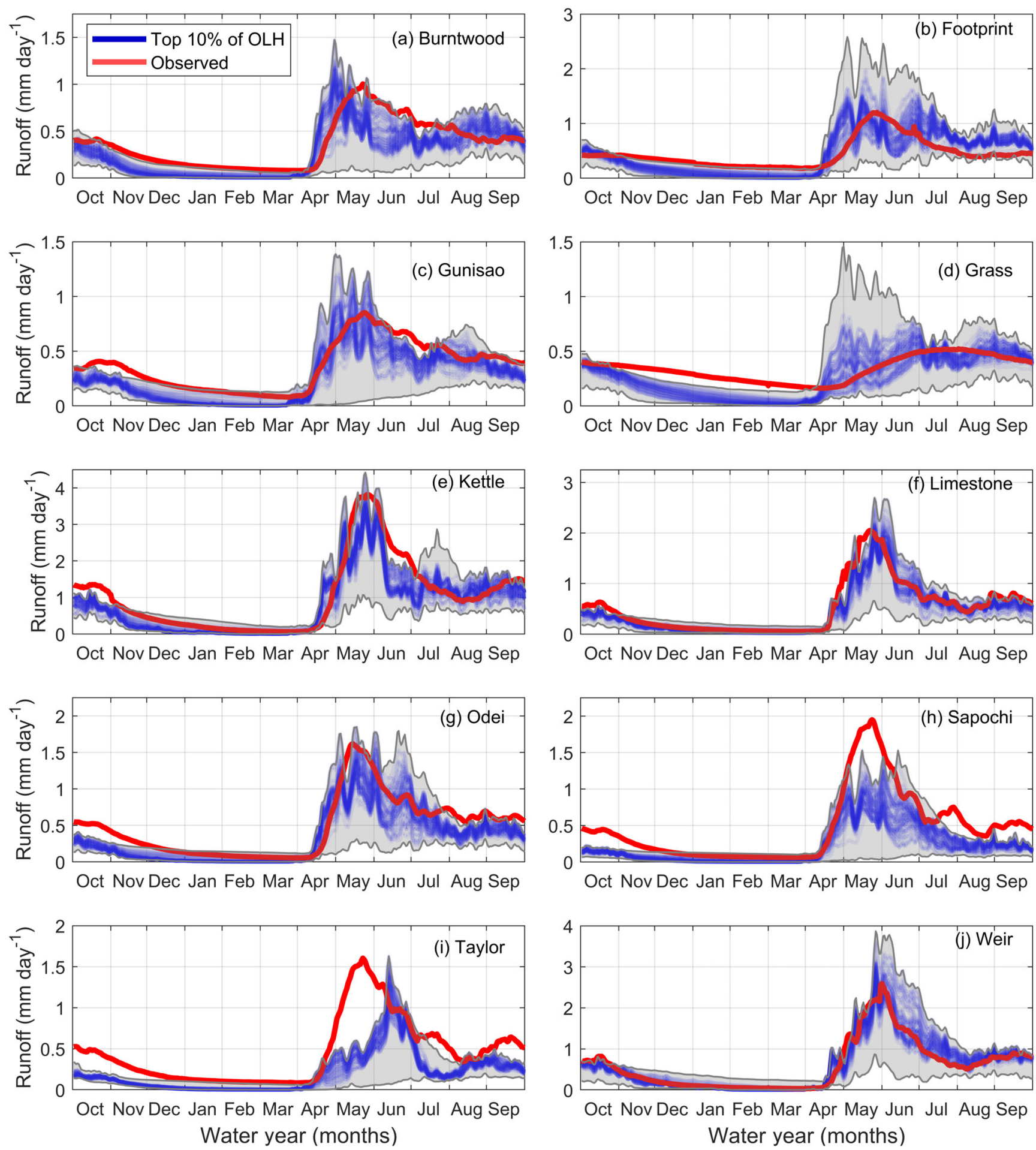

FIGURE 10 Streamflow prediction uncertainty associated with estimated parameters from the OLH. Top 10\% (shown in blue colour) of OLH samples, based on Kling-Gupta efficiency, used for the prediction of streamflow for all 10 sub-watersheds, water years 1981-2010. Note that $y$ axis scales vary between panels. Shaded area (grey colour) shows the envelope of variable infiltration capacity runs from $600 \mathrm{OLH}$ samples. OLH, orthogonal Latin hypercube

parameter range. However, the hydrograph uncertainty bounds, which come from the top $10 \%$ of OLH runs, associated with these parameter ranges do not cover the expected number of observed streamflow values (dark blue region in Figure 10). This can be argued as a problem of over conditioning the selected relationships between observed and modelled output (Bermúdez et al., 2017). The Footprint and Weir sub-watersheds have the widest uncertainty envelopes whereas the Burntwood, Limestone, Odei, Sapochi, and Taylor subwatersheds show relatively narrow uncertainty bounds from the OLH simulation. This may depend on watershed area, as parameter 
variation among a broad range of values over small sub-basins (e.g., Footprint and Weir) yields greater streamflow uncertainty than for relatively larger ones (e.g., Burntwood, Limestone, Odei, Sapochi, and Taylor). Even though the other $90 \%$ prediction uncertainty range (light grey region in Figure 10) captures all observations, it remains quite wide compared with observations and reveals a notable uncertainty range $\left(0.5-1 \mathrm{~mm} \mathrm{day}^{-1}\right)$ in the model parameters, as other conditions are static in this analysis.

\section{5 | DISCUSSION}

\section{1 | Input data uncertainty}

The underestimation in flows from the IDW VIC and ANUSPLIN VIC simulations reflect the precipitation undercatch and dry bias in these data sets over the LNRB (Lilhare et al., 2019). As the model resolution and other configuration (i.e., soil type, land use, etc.) are similar for all VIC simulations, different values of model performance metrics exhibit uncertainty associated only with input forcing data sets. These simulations show substantial disagreement in the run-off with observed hydrographs, especially in the Kettle, Limestone, Odei, Sapochi, and Weir sub-basins, owing to the dry bias and undercatch issues in the precipitation data. Consistent with our previous findings, the wet (warm) ERA-I and WFDEI precipitation (mean air temperature) over the LNRB in spring, summer, and autumn induce more surface run-off and snowmelt that overestimate simulated flows (Figure 4; Lilhare et al., 2019). Moreover, shifts in the hydrographs may be associated with warmer air temperatures over these sub-basins that cause earlier snowmelt run-off. Such variation in the simulated run-off, especially during the snowmelt period (April-July), is either due to the uncertain amount and timing of precipitation or air temperature in input forcing data sets (Lilhare et al., 2019).

Other sources of uncertainties in water budget estimation may be the dry (wet) bias in precipitation that results in poor calibration where model parameters cannot achieve optimal values due to less (excess) water availability. Consequently, these precipitation uncertainties among all sub-watersheds translate to a minimum (maximum) 14.0 (88.8) $\mathrm{mm}_{\text {year }}{ }^{-1}$ error in the water balance estimates. These results correspond well with those of Fekete et al. (2010) who found that the uncertainty in precipitation forcing translates to at least the same, or typically more substantial, uncertainty in runoff and related water balance terms. The simulated TR uncertainty is higher in spring and summer than fall and winter, which is mainly due to the more substantial seasonal variation in inter-data sets precipitation and air temperature. However, there remains much uncertainty in air temperature records over the LNRB from the different forcing data sets. This uncertainty can be translated into interseasonal water balance estimation through run-off and ET processes, which are more sensitive to air temperature. The sub-basins that are more susceptible to ET loss with relatively more surface water coverage, that is, the Grass and Gunisao, will, therefore, have higher uncertainty propagation from input data. This represents both time and space dimensionality to the uncertainty and plays a critical role in climate change studies where changes in run-off are most important.

Given that the domain average air temperature and precipitation differ across VIC forcings, the choice of VIC calibration and validation periods may induce uncertainty in water balance simulations. Therefore, calibration using different forcing data over 5-10 years may generate biases in simulated water balance conditions, as only a wet or dry period may be captured. Intercomparison of precipitation partitioning across various land surface models showed that specific representation and parameterizations for water balance components (i.e., ET and TR) were not consistent across models (Andresen et al., 2019). However, some models maintained similar run-off and precipitation ratios throughout the simulation; in contrast, VIC showed shifts from a run-off-dominated system to an ET-dominated system over permafrost regions in the Northern Hemisphere north of $45^{\circ} \mathrm{N}$ (Andresen et al., 2019).

\section{2 | Model parameter sensitivity and uncertainty assessment}

The sensitivity of model outputs to selected parameters is justified given the formulations of the variable infiltration and baseflow generation curve that form the foundation of the VIC architecture (Liang et al., 1994, 1996) and as these parameters are traditionally applied in model calibration (i.e., Elsner et al., 2010). As reported in previous studies, sensitivity to these parameters hold in both current and future climate scenarios (Bennett et al., 2018; Christensen \& Lettenmaier, 2007; Demaria et al., 2007). A previous effort used various objective functions and found that $\mathrm{b}_{\text {inf }}$ and D2 were the most sensitive parameters followed by the drainage parameter among $10 \mathrm{VIC}$ parameters across four American river basins of different hydroclimates (Demaria et al., 2007). Xie and Yuan (2006) manually varied four VIC parameters from $\pm 10 \%$ to $\pm 25 \%$ to perform SA over 12 watersheds in France, finding baseflow and soil depth related parameters as the most sensitive one. These studies either used manual analysis methods or limited objective functions at annual timescale to examine the parameter sensitivity. In contrast, we apply a more robust, automated, and efficient approach at seasonal and annual timescales to determine the parameter sensitivity and its seasonal importance over 10 subarctic watersheds. Moreover, the SA method takes multiple objective functions into account that provide more robust estimates of parameter sensitivity.

The high values of IVARS 50 for D2 are caused partly by the interaction of this parameter with other model parameters (e.g., soil profile and root depth) and its relatively large range of values. The Ds and $D s_{\max }$ parameters influence baseflow, which have a higher impact on low-flow predictions. Therefore, these parameters become important for NSE in some sub-basins (Grass and Footprint) as they control the timing of low flows. Moreover, in PBIAS, high values of D2 indicate its considerable interaction on model responses as D2 characterizes the seasonal soil moisture behaviour but by no means $b_{\text {inf }}$ as 
being perhaps also an important parameter over the LNRB. Overall, for PBIAS, $b_{\text {inf }}$ and D2 are influential parameters followed by $D_{\text {max }}$ This is due to the influence of all these parameters in controlling surface and subsurface water storages. In all sub-basins, D2 is more important than D3. This is perhaps because of (a) the third layer is much thicker than the other two layers and (b) the second layer has a larger control on infiltration and ET.

There is general agreement between the NSE and KGE sensitivity experiments over most sub-watersheds, particularly in identifying the most influential parameters. Nonetheless, parameter sensitivity depends on metric choice and varies significantly according to model performance metrics. For example, the D2 parameter is quite important for KGE and PBIAS in most of the rivers but has slightly less impact on NSE. This is because D2 controls baseflow and thus the timing of flows, which is important particularly for peak flows represented by NSE. However, flow timing is not important when assessing total flow volume represented by PBIAS. Similarly, $b_{\text {inf }}$ is less important for KGE and PBIAS but more influential for NSE over most sub-basins through its control of available infiltration capacity, thereby influencing peak flows and soil water volumes. Moreover, seasonality and wet or dry years may yield different SA results, which should be noted as a cautionary tale for using SA as a precalibration methodology. Consequently, to better understand the dominant controls on model behaviour, multiple criteria should be considered.

These results reinforce the well-known conclusion that for most effective SA results, one should select SA criteria in alignment with the final goals of the modelling application (e.g., flood forecasting, drought analysis, or water balance assessment). Regardless of the metric choice, often a limited number of parameters control most of the model response variations. This has important implications such as minimizing the dimensionality of the optimization process (i.e., calibration) through emphasis on a few influential parameters to generate reliable results. Even if fixed values for these influential parameters cannot be prescribed, any available information including observational data may reduce parameter ranges during calibration. This is generally true for all parameters and greatly increases the identifiability of our modelling application, which is often overlooked. Moreover, this also fits with the International Association of Hydrological Sciences' (IAHS) 23 unsolved problems in hydrology initiatives focused on understanding process changes, which control changing run-off response (Blöschl et al., 2019). Moreover, using these SA results, one can focus on specific model parameters and their value ranges, thus diminishing computational burdens, by fixing the value of non-essential parameters.

\section{6 | CONCLUSION}

This exercise provides valuable new insights into the internal functioning of models and allows the provision of impactful recommendations for improving development and application of the VIC model. In this respect, we found that daily precipitation is more important than air temperature for annual and seasonal water balance estimates. The choice of model performance metric significantly affects the sensitivity assessment. Therefore, to obtain indepth understanding of model behaviour, SA using multiple criteria should be adopted, which capture distinct characteristics of the model response.

SA results can be used more effectively when aligned with the final goals of the model application (e.g., flood forecasting and drought monitoring). SA results depend on various factors such as hydroclimatic conditions, model configuration, input forcing, land cover classes, initial state, vegetation parameters, and so forth, and these can have a large impact on model behaviour. We considered a full range of parameters that can influence their ratio of factor sensitivity if the range changes in other applications. SA can identify aspects of the model internal functioning that are counterintuitive and thus assist modellers to diagnose possible model deficiencies and make recommendations for end users. The calibration process identified a set of influential parameters that assists VIC users in reducing prediction uncertainty by providing a more robust, accurate, and less computationally intensive calibration effort. Overall, parameters for the second soil layer depth and variable infiltration curve dominate the control of streamflow prediction in VIC followed by the Ds and Ds $s_{\max }$ parameters. The VIC community may prioritize these parameters during model calibration for similar physical and climatic environments. Although this study focused on VARS sensitivity and OLH uncertainty analysis, a multicriteria SA approach under various conditions may lead to improved understanding of model structure, reductions in prediction uncertainty, and more efficient parameter calibration. Potential future work could investigate the effects of initial or boundary conditions and/or other model variables such as soil moisture or ET in model sensitivity assessments.

\section{AUTHOR CONTRIBUTIONS}

All authors designed the study. R. L. and S. P. developed the VARScoupled VIC MATLAB codes and methodology. R. L. extracted hydrometric data, performed VIC and VARS simulations, computed the hydrographs, performed the sensitivity and uncertainty analyses, and drafted figures with support from S. P., S. J. D., and T. A. S. R. L. wrote the manuscript with contributions from all co-authors, and all contributed to manuscript refinement and revisions.

\section{ACKNOWLEDGMENTS}

Financial and in-kind support for this research was provided by Manitoba Hydro, ArcticNet, and the Natural Sciences and Engineering Research Council of Canada (NSERC) through the BaySys project. Mark Gervais, Philip Slota, Mike Vieira, and Shane Wruth (Manitoba Hydro) provided helpful advice and logistical support throughout this work and beneficial reviews on an earlier version of the manuscript. Thanks to UNBC's NHG members Siraj UI Islam and Aseem Raj Sharma for providing access to and information on gridded climate data sets. Thanks to two anonymous reviewers and the handling editor for their constructive and insightful comments that led to a much improved paper. 


\section{DATA AVAILABILITY STATEMENT}

The forcing data that support the findings of this study are openly available online: for IDW at http://climate.weather.gc.ca/historical_data/search_historic_data_e.html, ANUSPLIN at https://cfs. nrcan.gc.ca/projects/3, NARR at https://www.esrl.noaa.gov/psd/ data/gridded/data.narr.html, ERA-I at https://apps.ecmwf.int/ datasets/data/interim-full-daily/levtype=sfc/, WFDEI at https://rda. ucar.edu/datasets/ds314.2/\#!description, and HydroGFD at https:// hypeweb.smhi.se. The hydrometric data from Water Survey of Canada are publicly available at https://wateroffice.ec.gc.ca. The VIC simulations are available upon request from the authors.

\section{ORCID}

Rajtantra Lilhare (D) https://orcid.org/0000-0002-6913-6024

Scott Pokorny (D) https://orcid.org/0000-0001-6665-5622

Stephen J. Déry (D) https://orcid.org/0000-0002-3553-8949

Tricia A. Stadnyk (D) https://orcid.org/0000-0002-2145-4963

Kristina A. Koenig (D) https://orcid.org/0000-0002-1570-3820

\section{REFERENCES}

Abebe, N. A., Ogden, F. L., \& Pradhan, N. R. (2010). Sensitivity and uncertainty analysis of the conceptual HBV rainfall-runoff model: Implications for parameter estimation. Journal of Hydrology, 389(3-4), 301-310.

Anderson, J., Chung, F., Anderson, M., Brekke, L., Easton, D., Ejeta, M., ... Snyder, R. (2008). Progress on incorporating climate change into management of California's water resources. Climatic Change, 87, 91-108.

Andresen, C. G., Lawrence, D. M., Wilson, C. J., McGuire, A. D., Koven, C., Schaefer, K., ... Zhang, W. (2019). Soil moisture and hydrology projections of the permafrost region: A model intercomparison. The Cryosphere Discussions, 1-20. https://doi.org/10.5194/tc-2019-144

Aster, R. C., Borchers, B., \& Thurber, C. H. (2013). Parameter estimation and inverse problems (2nd ed.). Retrieved from https://www.elsevier. com/books/parameter-estimation-and-inverse-problems/aster/978-012-385048-5

Bennett, K. E., Blanco, J. R. U., Jonko, A., Bohn, T. J., Atchley, A. L., Urban, N. M., \& Middleton, R. S. (2018). Global sensitivity of simulated water balance indicators under future climate change in the Colorado Basin. Water Resources Research, 54(1), 132-149. https://doi.org/10. 1002/2017WR020471

Berg, P., Donnelly, C., \& Gustafsson, D. (2018). Near-real-time adjusted reanalysis forcing data for hydrology. Hydrology and Earth System Sciences, 22(2), 989-1000. https://doi.org/10.5194/hess-22-989-2018

Bermúdez, M., Neal, J. C., Bates, P. D., Coxon, G., Freer, J. E., Cea, L., \& Puertas, J. (2017). Quantifying local rainfall dynamics and uncertain boundary conditions into a nested regional-local flood modeling system. Water Resources Research, 53(4), 2770-2785. https://doi.org/10. 1002/2016WR019903

Beven, K., \& Binley, A. (1992). The future of distributed models: Model calibration and uncertainty prediction. Hydrological Processes, 6(3), 279-298. https://doi.org/10.1002/hyp.3360060305

Blöschl, G., Bierkens, M. F. P., Chambel, A., Cudennec, C., Destouni, G., Fiori, A., ... Zhang, Y. (2019). Twenty-three unsolved problems in hydrology (UPH) - A community perspective. Hydrological Sciences Journal, 64(10), 1141-1158. https://doi.org/10.1080/02626667. 2019.1620507

Boucher, O., \& Best, M. (2010). The WATCH forcing data 1958-2001: A meteorological forcing dataset for land surface- and hydrologicalmodels. In WATCH technical report. Wallingford Oxfordshire, UK: Water and Global Change.
Bowling, L. C., \& Lettenmaier, D. P. (2010). Modeling the effects of lakes and wetlands on the water balance of arctic environments. Journal of Hydrometeorology, 11(2), 276-295. https://doi.org/10.1175/2009 JHM1084.1

Bowling, L. C., Lettenmaier, D. P., Nijssen, B., Graham, L. P., Clark, D. B., El Maayar, M., ... Yang, Z. (2003). Simulation of high-latitude hydrological processes in the Torne-Kalix basin: PILPS phase 2 (e): 1: Experiment description and summary intercomparisons. Global and Planetary Change, 38(1), 1-30.

Cherkauer, K. A., \& Lettenmaier, D. P. (1999). Hydrologic effects of frozen soils in the upper Mississippi River basin. Journal of Geophysical Research: Atmospheres, 104(D16), 19599-19610.

Cherkauer, K. A., \& Lettenmaier, D. P. (2003). Simulation of spatial variability in snow and frozen soil. Journal of Geophysical Research: Atmospheres, 108(D22), 8858. https://doi.org/10.1029/2003JD003575

Christensen, N. S., \& Lettenmaier, D. P. (2007). A multimodel ensemble approach to assessment of climate change impacts on the hydrology and water resources of the Colorado River basin. Hydrology and Earth System Sciences, 11(4), 1417-1434. https://doi.org/10.5194/hess-111417-2007

Cosby, B. J., Hornberger, G. M., Clapp, R. B., \& Ginn, T. (1984). A statistical exploration of the relationships of soil moisture characteristics to the physical properties of soils. Water Resources Research, 20(6), 682-690.

Dee, D. P., Uppala, S. M., Simmons, A. J., Berrisford, P., Poli, P., Kobayashi, S., ... Vitart, F. (2011). The ERA-interim reanalysis: Configuration and performance of the data assimilation system. Quarterly Journal of the Royal Meteorological Society, 137(656), 553-597. https://doi. org/10.1002/qj.828

Demaria, E. M., Nijssen, B., \& Wagener, T. (2007). Monte Carlo sensitivity analysis of land surface parameters using the variable infiltration capacity model. Journal of Geophysical Research: Atmospheres, 112, D11113. https://doi.org/10.1029/2006JD007534

Döll, P., Kaspar, F., \& Lehner, B. (2003). A global hydrological model for deriving water availability indicators: Model tuning and validation. Journal of Hydrology, 270(1), 105-134.

Duan, Q., Sorooshian, S., \& Gupta, V. (1992). Effective and efficient global optimization for conceptual rainfall-runoff models. Water Resources Research, 28(4), 1015-1031. https://doi.org/10.1029/91WR02985

Elsner, M. M., Cuo, L., Voisin, N., Deems, J. S., Hamlet, A. F., Vano, J. A., ... Lettenmaier, D. P. (2010). Implications of 21st century climate change for the hydrology of Washington State. Climatic Change, 102(1-2), 225-260.

Eum, H.-I., Dibike, Y., Prowse, T., \& Bonsal, B. (2014). Inter-comparison of high-resolution gridded climate data sets and their implication on hydrological model simulation over the Athabasca Watershed, Canada. Hydrological Processes, 28(14), 4250-4271.

Fekete, B. M., Vörösmarty, C. J., Roads, J. O., \& Willmott, C. J. (2004). Uncertainties in precipitation and their impacts on runoff estimates. Journal of Climate, 17(2), 294-304.

Fekete, B. M., Wisser, D., Kroeze, C., Mayorga, E., Bouwman, L., Wollheim, W. M., \& Vörösmarty, C. (2010). Millennium ecosystem assessment scenario drivers (1970-2050): Climate and hydrological alterations. Global Biogeochemical Cycles, 24(4). Washington, D.C.: American Geophysical Union. https://doi.org/10.1029/2009GB00 3593

Fowler, H. J., Ekström, M., Blenkinsop, S., \& Smith, A. P. (2007). Estimating change in extreme European precipitation using a multimodel ensemble. Journal of Geophysical Research: Atmospheres, 112, D18104. https://doi.org/10.1029/2007JD008619

Fowler, H. J., \& Kilsby, C. G. (2007). Using regional climate model data to simulate historical and future river flows in Northwest England. Climatic Change, 80(3-4), 337-367.

Frey, H. C., \& Patil, S. R. (2002). Identification and review of sensitivity analysis methods. Risk Analysis, 22(3), 553-578. https://doi.org/10. 1111/0272-4332.00039 
Gan, Y., Duan, Q., Gong, W., Tong, C., Sun, Y., Chu, W., ... Di, Z. (2014). A comprehensive evaluation of various sensitivity analysis methods: $A$ case study with a hydrological model. Environmental Modelling \& Software, 51, 269-285. https://doi.org/10.1016/j.envsoft.2013.09.031

Gemmer, M., Becker, S., \& Jiang, T. (2004). Observed monthly precipitation trends in China 1951-2002. Theoretical and Applied Climatology, 77 (1-2), 39-45. https://doi.org/10.1007/s00704-003-0018-3

Gerten, D., Schaphoff, S., Haberlandt, U., Lucht, W., \& Sitch, S. (2004). Terrestrial vegetation and water balance-Hydrological evaluation of a dynamic global vegetation model. Journal of Hydrology, 286(1), 249-270.

Goldberg, D. E. (1989). Genetic algorithms in search, optimization, and machine learning. Reading, MA: Addison Wesley Publishing Company.

Gupta, H. V., Kling, H., Yilmaz, K. K., \& Martinez, G. F. (2009). Decomposition of the mean squared error and NSE performance criteria: Implications for improving hydrological modelling. Journal of Hydrology, 377 (1-2), 80-91. https://doi.org/10.1016/j.jhydrol.2009.08.003

Hill, M. C., \& Tiedeman, C. R. (2007). Effective groundwater model calibration: With analysis of data, sensitivities, predictions, and uncertainty. Hoboken, NJ: John Wiley \& Sons.

Hopkinson, R. F., McKenney, D. W., Milewska, E. J., Hutchinson, M. F., Papadopol, P., \& Vincent, L. A. (2011). Impact of aligning climatological day on gridding daily maximum-minimum temperature and precipitation over Canada. Journal of Applied Meteorology and Climatology, 50 (8), 1654-1665.

Hostetler, S. W. (1991). Simulation of lake ice and its effect on the latePleistocene evaporation rate of Lake Lahontan. Climate Dynamics, 6(1), 43-48. https://doi.org/10.1007/BF00210581

Hostetler, S. W., \& Bartlein, P. J. (1990). Simulation of lake evaporation with application to modeling lake level variations of Harney-Malheur Lake, Oregon. Water Resources Research, 26(10), 2603-2612. https:// doi.org/10.1029/WR026i010p02603

Hundecha, Y., St-Hilaire, A., Ouarda, T., El Adlouni, S., \& Gachon, P. (2008). A nonstationary extreme value analysis for the assessment of changes in extreme annual wind speed over the Gulf of St. Lawrence, Canada. Journal of Applied Meteorology and Climatology, 47(11), 2745-2759.

Iman, R. L., \& Helton, J. C. (1988). An investigation of uncertainty and sensitivity analysis techniques for computer models. Risk Analysis, 8(1), 71-90. https://doi.org/10.1111/j.1539-6924.1988.tb01155.x

Islam, S. U., \& Déry, S. J. (2017). Evaluating uncertainties in modelling the snow hydrology of the Fraser River basin, British Columbia, Canada. Hydrology and Earth System Sciences, 21(3), 1827-1847. https://doi. org/10.5194/hess-21-1827-2017

Kang, D. H., Gao, H., Shi, X., Islam, S. u., \& Déry, S. J. (2016). Impacts of a rapidly declining mountain snowpack on streamflow timing in Canada's Fraser River basin. Scientific Reports, 6, 19299. https://doi. org/10.1038/srep19299

Kavetski, D., Kuczera, G., \& Franks, S. W. (2006). Calibration of conceptual hydrological models revisited: 2. Improving optimisation and analysis. Journal of Hydrology, 320(1), 187-201. https://doi.org/10.1016/j. jhydrol.2005.07.013

Li, L., \& Xu, C.-Y. (2014). The comparison of sensitivity analysis of hydrological uncertainty estimates by GLUE and Bayesian method under the impact of precipitation errors. Stochastic Environmental Research and Risk Assessment, 28(3), 491-504. https://doi.org/10.1007/s00477-013-0767-1

Liang, X., \& Guo, J. (2003). Intercomparison of land-surface parameterization schemes: Sensitivity of surface energy and water fluxes to model parameters. Journal of Hydrology, 279(1), 182-209. https://doi.org/10. 1016/S0022-1694(03)00168-9

Liang, X., Lettenmaier, D. P., Wood, E. F., \& Burges, S. J. (1994). A simple hydrologically based model of land surface water and energy fluxes for general circulation models. Journal of Geophysical Research: Atmospheres, 99(D7), 14415-14428.

Liang, X., Wood, E. F., \& Lettenmaier, D. P. (1996). Surface soil moisture parameterization of the VIC-2L model: Evaluation and modification. Global and Planetary Change, 13(1), 195-206.
Liang, X., Wood, E. F., \& Lettenmaier, D. P. (1999). Modeling ground heat flux in land surface parameterization schemes. Journal of Geophysical Research: Atmospheres, 104(D8), 9581-9600. https://doi.org/10. 1029/98JD02307

Liang, X., Xie, Z., \& Huang, M. (2003). A new parameterization for surface and groundwater interactions and its impact on water budgets with the variable infiltration capacity (VIC) land surface model. Journal of Geophysical Research: Atmospheres, 108(D16), 8613. https://doi.org/ 10.1029/2002JD003090

Lilhare, R., Déry, S. J., Pokorny, S., Stadnyk, T. A., \& Koenig, K. A. (2019). Inter-comparison of multiple hydro-climatic datasets across the lower Nelson River basin, Manitoba, Canada. Atmosphere-Ocean, 57(4), 262-278. https://doi.org/10.1080/07055900.2019.1638226

Liu, Y., \& Gupta, H. V. (2007). Uncertainty in hydrologic modeling: Toward an integrated data assimilation framework. Water Resources Research, 43, W07401. https://doi.org/10.1029/2006WR005756

Mao, D., \& Cherkauer, K. A. (2009). Impacts of land-use change on hydrologic responses in the Great Lakes region. Journal of Hydrology, 374(1), 71-82.

Maurer, E. P., Wood, A. W., Adam, J. C., Lettenmaier, D. P., \& Nijssen, B. (2002). A long-term hydrologically based dataset of land surface fluxes and states for the conterminous United States. Journal of Climate, 15 (22), 3237-3251.

Mesinger, F., DiMego, G., Kalnay, E., Mitchell, K., Shafran, P. C., Ebisuzaki, W., ... Shi, W. (2006). North American regional reanalysis. Bulletin of the American Meteorological Society, 87(3), 343-360. https://doi.org/10.1175/BAMS-87-3-343

Miller, D. A., \& White, R. A. (1998). A conterminous United States multilayer soil characteristics dataset for regional climate and hydrology modeling. Earth Interactions, 2(2), 1-26.

Mishra, V., \& Lilhare, R. (2016). Hydrologic sensitivity of Indian subcontinental river basins to climate change. Global and Planetary Change, 139, 78-96. https://doi.org/10.1016/j.gloplacha.2016.01.003

Myneni, R. B., Ramakrishna, R., Nemani, R., \& Running, S. W. (1997). Estimation of global leaf area index and absorbed PAR using radiative transfer models. IEEE Transactions on Geoscience and Remote Sensing, 35(6), 1380-1393.

Nash, J., \& Sutcliffe, J. V. (1970). River flow forecasting through conceptual models part I-A discussion of principles. Journal of Hydrology, 10(3), 282-290.

Natural Resources Canada. (2010, December 31). Permafrost. Retrieved December 23, 2016, from http://geogratis.gc.ca/api/en/nrcan-rncan/ ess-sst/dc7107c0-8893-11e0-aa10-6cf049291510.html

Natural Resources Canada. (2014). Regional, national and international climate modeling | Forests | Natural Resources Canada: Introduction. Retrieved November 3, 2016, from http://cfs.nrcan.gc.ca/projects/3? lang=en_CA

Natural Resources Canada. (2016). Potential Evapotranspiration-Open Government Portal. Retrieved April 9, 2018, from https://open. canada.ca/data/en/dataset/a650fb95-1104-504b-a344Ofe05877b7cf

Nijssen, B., Lettenmaier, D. P., Liang, X., Wetzel, S. W., \& Wood, E. F. (1997). Streamflow simulation for continental-scale river basins. Water Resources Research, 33(4), 711-724. https://doi.org/10.1029/96W R03517

Nijssen, B., Schnur, R., \& Lettenmaier, D. P. (2001). Global retrospective estimation of soil moisture using the variable infiltration capacity land surface model, 1980-93. Journal of Climate, 14(8), 1790-1808.

North American Land Change Monitoring System. (2010). 2010 North American Land Cover at $250 \mathrm{~m}$ spatial resolution. Produced by Natural Resources Canada/Canadian Center for Remote Sensing (NRCan/ CCRS), United States Geological Survey (USGS); Insituto Nacional de Estadística y Geografía (INEGI), Comisión Nacional para el Conocimiento y Uso de la Biodiversidad (CONABIO) and Comisión Nacional Forestal (CONAFOR). Retrieved April 14, 2017, from The 
USGS Land Cover Institute (LCl) website: http://www.cec.org/toolsand-resources/map-files/land-cover-2010

Patterson, J. C., \& Hamblin, P. F. (1988). Thermal simulation of a lake with winter ice cover. Limnology and Oceanography, 33(3), 323-338. https://doi.org/10.4319/lo.1988.33.3.0323

Pavelsky, T. M., \& Smith, L. C. (2006). Intercomparison of four global precipitation data sets and their correlation with increased Eurasian river discharge to the Arctic Ocean. Journal of Geophysical Research: Atmospheres, 111, D21112. https://doi.org/10.1029/ 2006JD007230

Razavi, S., \& Gupta, H. V. (2016a). A new framework for comprehensive, robust, and efficient global sensitivity analysis: 1. Theory. Water Resources Research, 52(1), 423-439. https://doi.org/10.1002/ 2015WR017558

Razavi, S., \& Gupta, H. V. (2016b). A new framework for comprehensive, robust, and efficient global sensitivity analysis: 2. Application. Water Resources Research, 52(1), 440-455. https://doi.org/10.1002/2015 WR017559

Razavi, S., Sheikholeslami, R., Gupta, H. V., \& Haghnegahdar, A. (2019). VARS-TOOL: A toolbox for comprehensive, efficient, and robust sensitivity and uncertainty analysis. Environmental Modelling \& Software, 112, 95-107. https://doi.org/10.1016/j.envsoft.2018.10.005

Reed, S., Koren, V., Smith, M., Zhang, Z., Moreda, F., Seo, D.-J., \& DMIP Participants (2004). Overall distributed model intercomparison project results. Journal of Hydrology, 298(1), 27-60.

Sabarly, F., Essou, G., Lucas-Picher, P., Poulin, A., \& Brissette, F. (2016). Use of four reanalysis datasets to assess the terrestrial branch of the water cycle over Quebec, Canada. Journal of Hydrometeorology, 17(5), 1447-1466.

Sauchyn, D., Vanstone, J., \& Perez-Valdivia, C. (2011). Modes and forcing of hydroclimatic variability in the upper North Saskatchewan River basin since 1063. Canadian Water Resources Journal, 36(3), 205-217. https://doi.org/10.4296/cwrj3603889

Seager, R., Neelin, D., Simpson, I., Liu, H., Henderson, N., Shaw, T., ... Cook, B. (2014). Dynamical and thermodynamical causes of large-scale changes in the hydrological cycle over North America in response to global warming. Journal of Climate, 27(20), 7921-7948.

Shafii, M., Tolson, B., \& Matott, L. S. (2015). Addressing subjective decision-making inherent in GLUE-based multi-criteria rainfall-runoff model calibration. Journal of Hydrology, 523, 693-705. https://doi.org/ 10.1016/j.jhydrol.2015.01.051

Sheffield, J., \& Wood, E. F. (2007). Characteristics of global and regional drought, 1950-2000: Analysis of soil moisture data from off-line simulation of the terrestrial hydrologic cycle. Journal of Geophysical Research: Atmospheres, 112, D17115. https://doi.org/10.1029/2006 JD008288

Shepard, D. (1968). A two-dimensional interpolation function for irregularly-spaced data. Proceedings of the 1968 ACM National Conference (pp. 517-524). New York. http://dx.doi.org/10.1145/800186. 810616

Shi, X., Wood, A. W., \& Lettenmaier, D. P. (2008). How essential is hydrologic model calibration to seasonal streamflow forecasting? Journal of Hydrometeorology, 9(6), 1350-1363. https://doi.org/10.1175/2008 JHM1001.1

Stedinger, J. R., Vogel, R. M., Lee, S. U., \& Batchelder, R. (2008). Appraisal of the generalized likelihood uncertainty estimation (GLUE) method. Water Resources Research, 44(12), W00B06. https://doi.org/10.1029/ 2008WR006822

Tapiador, F. J., Turk, F. J., Petersen, W., Hou, A. Y., García-Ortega, E., Machado, L. A., ... Huffman, G. J. (2012). Global precipitation measurement: Methods, datasets and applications. Atmospheric Research, 104, 70-97.

Tobin, C., Nicotina, L., Parlange, M. B., Berne, A., \& Rinaldo, A. (2011). Improved interpolation of meteorological forcings for hydrologic applications in a Swiss alpine region. Journal of Hydrology, 401(1), 77-89.

United States Geological Survey. (2013). Shuttle Radar Topography Mission (SRTM) 1 Arc-Second Global | The Long Term Archive. Retrieved April 6, 2017, from https://Ita.cr.usgs.gov/SRTM1Arc

USACE. (1956). "Snow hydrology" summary report of the snow investigations. Portland, Oregon: North Pacific Division, US Army Corps of Engineers.

Van Griensven, A., Meixner, T., Grunwald, S., Bishop, T., Diluzio, M., \& Srinivasan, R. (2006). A global sensitivity analysis tool for the parameters of multi-variable catchment models. Journal of Hydrology, 324 (1-4), 10-23. https://doi.org/10.1016/j.jhydrol.2005.09.008

Vrugt, J. A., Diks, C. G., Gupta, H. V., Bouten, W., \& Verstraten, J. M. (2005). Improved treatment of uncertainty in hydrologic modeling: Combining the strengths of global optimization and data assimilation. Water Resources Research, 41(1), W01017. https://doi.org/10.1029/ 2004WR003059

Vrugt, J. A., Gupta, H. V., Bouten, W., \& Sorooshian, S. (2003). A shuffled complex evolution Metropolis algorithm for optimization and uncertainty assessment of hydrologic model parameters. Water Resources Research, 39(8), 1201. https://doi.org/10.1029/2002WR001642

Wagener, T., \& Gupta, H. V. (2005). Model identification for hydrological forecasting under uncertainty. Stochastic Environmental Research and Risk Assessment, 19(6), 378-387.

Wang, A., Bohn, T. J., Mahanama, S. P., Koster, R. D., \& Lettenmaier, D. P. (2009). Multimodel ensemble reconstruction of drought over the continental United States. Journal of Climate, 22(10), 2694-2712.

Water Survey of Canada. (2016). Home-Water Office-Environment Canada. Retrieved January 4, 2017, from http://wateroffice.ec.gc.ca/

Weedon, G. P., Balsamo, G., Bellouin, N., Gomes, S., Best, M. J., \& Viterbo, P. (2014). The WFDEI meteorological forcing data set: WATCH forcing data methodology applied to ERA-interim reanalysis data. Water Resources Research, 50(9), 7505-7514.

Williams, G. P., \& Gold, L. W. (1976). Ground temperatures. CBD-180. Institute for Research in Construction. Originally Published, (July). https://doi.org/10.4224/40000712

Woo, M.-K., \& Thorne, R. (2006). Snowmelt contribution to discharge from a large mountainous catchment in subarctic Canada. Hydrological Processes, 20(10), 2129-2139.

Xie, Z., \& Yuan, F. (2006). A parameter estimation scheme of the land surface model VIC using the MOPEX databases. IAHS Publication, 307, 169-179.

Yapo, P. O., Gupta, H. V., \& Sorooshian, S. (1998). Multi-objective global optimization for hydrologic models. Journal of Hydrology, 204(1-4), 83-97. https://doi.org/10.1016/S0022-1694(97)00107-8

Zhang, J. L., Li, Y. P., Huang, G. H., Wang, C. X., \& Cheng, G. H. (2016). Evaluation of uncertainties in input data and parameters of a hydrological model using a Bayesian framework: A case study of a snowmeltprecipitation-driven watershed. Journal of Hydrometeorology, 17(8), 2333-2350. https://doi.org/10.1175/JHM-D-15-0236.1

\section{SUPPORTING INFORMATION}

Additional supporting information may be found online in the Supporting Information section at the end of this article.

How to cite this article: Lilhare R, Pokorny S, Déry SJ, Stadnyk TA, Koenig KA. Sensitivity analysis and uncertainty assessment in water budgets simulated by the variable infiltration capacity model for Canadian subarctic watersheds. Hydrological Processes. 2020;34:2057-2075. https://doi.org/ 10.1002/hyp.13711 